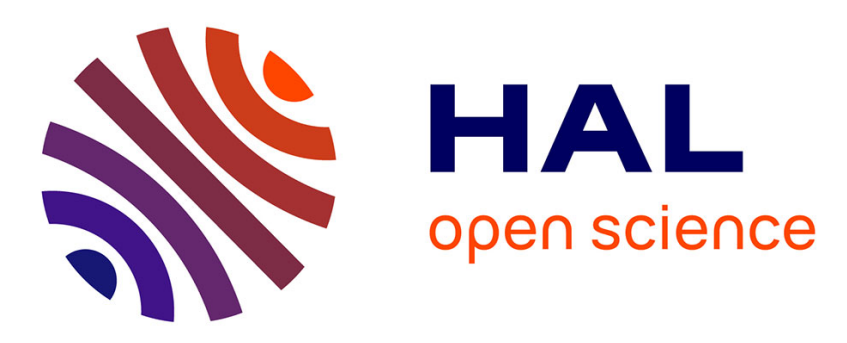

\title{
Thallium Transfer from Hydrochloric Acid Media into Pure Ionic Liquids
}

Evgeny E Tereshatov, Maria Yu Boltoeva, Valerie Mazan, Merinda F Volia, Charles M Folden

\section{- To cite this version:}

Evgeny E Tereshatov, Maria Yu Boltoeva, Valerie Mazan, Merinda F Volia, Charles M Folden. Thallium Transfer from Hydrochloric Acid Media into Pure Ionic Liquids. Journal of Physical Chemistry B, 2016, 120 (9), pp.2311-2322. 10.1021/acs.jpcb.5b08924 . hal-03009879

\section{HAL Id: hal-03009879 https://hal.science/hal-03009879}

Submitted on 17 Nov 2020

HAL is a multi-disciplinary open access archive for the deposit and dissemination of scientific research documents, whether they are published or not. The documents may come from teaching and research institutions in France or abroad, or from public or private research centers.
L'archive ouverte pluridisciplinaire HAL, est destinée au dépôt et à la diffusion de documents scientifiques de niveau recherche, publiés ou non, émanant des établissements d'enseignement et de recherche français ou étrangers, des laboratoires publics ou privés. 


\title{
Thallium Transfer from Hydrochloric Acid Media into Pure Ionic Liquids
}

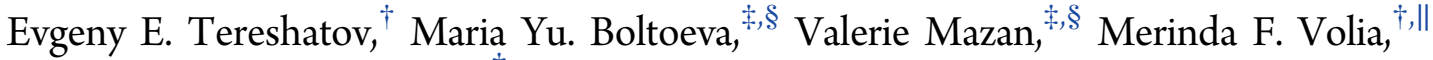 \\ and Charles M. Folden, III* ${ }^{*} \dagger$ \\ ${ }^{\dagger}$ Cyclotron Institute, Texas A\&M University, College Station, Texas 77843 United States \\ ${ }^{\ddagger}$ IPHC, Université de Strasbourg, Strasbourg, 67037 France \\ ${ }^{\S}$ CNRS, Strasbourg, 67037 France \\ "Department of Nuclear Engineering, Texas A\&M University, College Station, Texas 77843 United States
}

\section{Supporting Information}

ABSTRACT: Pure hydrophobic ionic liquids are known to extract metallic species from aqueous solutions. In this work we have systematically investigated thallium $(\mathrm{Tl})$ extraction from aqueous hydrochloric acid $(\mathrm{HCl})$ solutions into six pure fluorinated ionic liquids, namely imidazolium- and pyrrolidinium-based ionic liquids with bis(trifluoromethanesulfonyl)imide and bis(fluorosulfonyl)imide anions. The dependence of the $\mathrm{Tl}$ extraction efficiency on the structure and composition of the ionic liquid ions, metal oxidation state, and initial metal and aqueous acid concentrations have been studied. Tl concentrations were on the order of picomolar (analyzed using radioactive tracers) and millimolar (analyzed using inductively coupled plasma mass spectrometry). The extraction of the cationic thallium species $\mathrm{Tl}^{+}$is higher for ionic liquids with more hydrophilic cations, while for the $\mathrm{TlX}_{z}^{3-z}$ anionic species (where $\mathrm{X}=\mathrm{Cl}^{-}$and/or $\mathrm{Br}^{-}$), the extraction efficiency is greater for ionic liquids with more hydrophobic

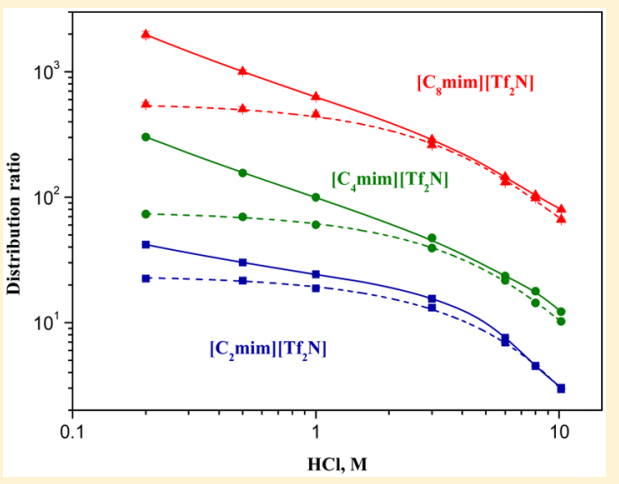
cations. The highest distribution value of $\mathrm{Tl}(\mathrm{III})$ was approximately 2000 . An improved mathematical model based on ion exchange and ion pair formation mechanisms has been developed to describe the coextraction of two different anionic species, and the relative contributions of each mechanism have been determined.

\section{INTRODUCTION}

The recently published report "Thallium: 2015 World Market Review and Forecast", prepared by Merchant Research \& Consulting Ltd., indicates that China, Kazakhstan, and Russia are the world's top producers of primary thallium. ${ }^{1}$ According to this study, the world demand for this metal is expected to grow slowly through 2018, due to stable needs from different industries, such as liquid crystal display fabrication, ${ }^{2}$ the fiber optic industry ${ }^{3,4}$ and glass lens production. ${ }^{5}$ One of the largest applications of thallium is the production of contrast agents for cardiological imaging exams by healthcare companies. ${ }^{6-8}$ An accompanying problem of thallium production is its toxicity ${ }^{9-11}$ and environment pollution. ${ }^{12-14}$ Thallium is a highly poisonous $^{15-17}$ and biogeochemically mobile metal. ${ }^{18-21}$ Such behavior is explained by the fact that monovalent thallium is chemically similar to potassium due to their similar ionic radii. $^{22,23}$ The toxicity of $\mathrm{Tl}(\mathrm{III})$ (also found in the environment) is higher than that of thermodynamically stable $\mathrm{Tl}(\mathrm{I}){ }^{24,25}$ Thus, the content of thallium in environmental systems has to be strongly regulated and controlled. A previous study ${ }^{18}$ reviewed worldwide standards for thallium contamination levels in soil (Canada and Switzerland, $1 \mathrm{mg} / \mathrm{kg}$ ); occupational exposure limits in air (Argentina, Mexico, United States, Canada, U.K., and Germany, $0.1 \mathrm{mg} / \mathrm{m}^{3}$, and Russia, $\left.0.01 \mathrm{mg} / \mathrm{m}^{3}\right)$; and maximum contaminant levels in drinking water (United States, $2 \mathrm{mg} / \mathrm{m}^{3}$ ).

Methods for thallium preconcentration and determination include well-known spectrophotometric, ${ }^{26,27}$ ion exchange, ${ }^{28,29}$ and liquid-liquid extraction techniques. ${ }^{30,31}$ One novel method is ionic liquid-based extraction, ${ }^{32-34}$ where an ionic liquid (IL) is a salt with a melting point below $100{ }^{\circ} \mathrm{C}$ and sometimes even below room temperature (so-called "room temperature ionic liquids"). ILs are largely made of ions (usually a bulk organic cation and an inorganic or organic anion) and short-lived ion pairs. ${ }^{35}$ These new ionic solvents are regarded as a good alternative to traditional organic solvents due to their attractive physicochemical properties such as negligible vapor pressure, high thermal and chemical stability, low toxicity, etc. Moreover, the enormous variety of ILs and their properties allow such compounds to have applications in the field of liquid-liquid extraction as diluents, pure extracting agents, and dopants to conventional organic phases. There are a few articles published in the past several years that are devoted to mono- and trivalent thallium extraction in IL media with and without an extracting

Received: September 13, 2015

Revised: January 14, 2016

Published: January 15, 2016 
agent. Extraction of $\mathrm{Tl}(\mathrm{I})$ was tested by a variety of pure pyridinium, pyrrolidinium, and piperidinium-based ILs with fluorinated anions [mostly bis(trifluoromethanesulfonyl)imide], and the corresponding distribution ratios were found to be below 2. ${ }^{36}$ A functionalized polymer impregnated with trihexyltetradecylphosphonium chloride, 1-octyl-3-methylimidazolium tetrafluoroborate and 1-butyl-3-methylimidazolium hexafluorophosphate ionic liquids was studied for $\mathrm{Tl}(\mathrm{I})$ adsorption. ${ }^{37}$ The authors of this article concluded that imidazolium-based ILs are more efficient than phosphoniumbased one. And among the first group of ILs considered, ones with longer alkyl chains showed higher efficiency, although the anionic parts were not the same. Monovalent thallium was extracted into a 1-hexyl-3-methylimidazolium hexafluorophosphate ionic liquid containing dicyclohexyl-18-crown-6, and at least $94 \%$ recovery was achieved. ${ }^{38}$ The extraction of $\mathrm{Tl}(\mathrm{III})$ was investigated in the presence of the 1-hexyl-3-methylimidazolium hexafluorophosphate ${ }^{39}$ and trihexyltetradecylphosphonium chloride ${ }^{40}$ ILs and their mixture, ${ }^{41}$ with a recovery of $96 \%$ in the case of pure ILs and $77 \%$ for the combination of ILs, respectively. In our previous work, ${ }^{42}$ the extraction of thallium from $\mathrm{HCl}$ solution into both pure 1-butyl-3-methylimidazolium bis(trifluoromethanesulfonyl)imide and its mixture with $30 \%$ (v/v) of tri- $n$-butyl phosphate (TBP) was studied. Distribution ratios of $\mathrm{Tl}(\mathrm{I})$ in these two extraction systems were below 0.1 . $\mathrm{Tl}$ (III) was extracted quantitatively both into pure ionic liquid with a distribution ratio $D_{\mathrm{Tl}(\mathrm{III})}$ of up to 300 and into an IL-TBP mixture with $D_{\mathrm{Tl}(\mathrm{III})}>2000$. Thus, pure bis(trifluoromethanesulfonyl)imide-based ILs look promising for metal extraction, and this approach makes the entire process favorable due to the absence of toxic organic solvents and conventional extracting agents, and should be considered as an evolutional step toward green chemistry.

Published articles regarding metal extraction into pure ILs contain fragmentary data on some elements such as iron, ${ }^{43}$ zinc, ${ }^{43}$ cadmium, ${ }^{43}$ iridium, ${ }^{44}$ platinum, ${ }^{45-47}$ gold, ${ }^{47-49}$ mercury, $^{50,51}$ lead, $^{52}$ cerium, $^{53}$ neodymium, ${ }^{54}$ europium, ${ }^{54}$ and plutonium. ${ }^{55,56}$ Obviously, knowledge in the field of liquidliquid extraction using pure ILs has to be extended. Here, we extend our previous study in order to establish the extraction mechanism and report experimental results on thallium extraction into various hydrophobic ionic liquids. Understanding the mechanism of pure IL-based processes, taking into account the key role of cations and anions of the organic salts, reveals opportunities to optimize parameters and conditions for efficient metal extraction and determination of thallium by means of ecofriendly media.

\section{EXPERIMENTAL SECTION}

Chemical Reagents. High-purity grade (99.5\%) 1-alkyl-3methylimidazolium bis(trifluoromethanesulfonyl)imide ionic liquids (henceforth indicated as $\left[\mathrm{C}_{n} \operatorname{mim}\right]\left[\mathrm{Tf}_{2} \mathrm{~N}\right]$, where $n=$ 2,4 , and 8), 1-propyl-2,3-dimethylimidazolium bis (trifluoromethanesulfonyl)imide (indicated as $\left.\left[\mathrm{C}_{3} \mathrm{C}_{1} \mathrm{mim}\right]\left[\mathrm{Tf}_{2} \mathrm{~N}\right]\right), \quad N$-propyl-N-methylpyrrolidinium bis (trifluoromethanesulfonyl)imide (indicated as $\left[\mathrm{C}_{3} \mathrm{C}_{1}\right.$ pyrr $\left.]\left[\mathrm{Tf}_{2} \mathrm{~N}\right]\right)$, 1-ethyl-3-methylimidazolium bis(fluorosulfonyl)imide (indicated as $\left[\mathrm{C}_{2} \mathrm{mim}\right][\mathrm{FSI}]$ ), and $\mathrm{Li}\left[\mathrm{Tf}_{2} \mathrm{~N}\right]$ salt $(>99 \%$ purity) were purchased from Solvionic (Toulouse, France). Concentrated hydrochloric acid, saturated $3 \%(\mathrm{w} / \mathrm{v})$ bromine and $0.3 \%(\mathrm{w} / \mathrm{v})$ chlorine water, and thallium(III) chloride hydrate were of analytical grade. All chemical reagents were used as received without any further purification. Figure 1 shows chemical structures of the ionic liquids used in present study. Their physicochemical character-

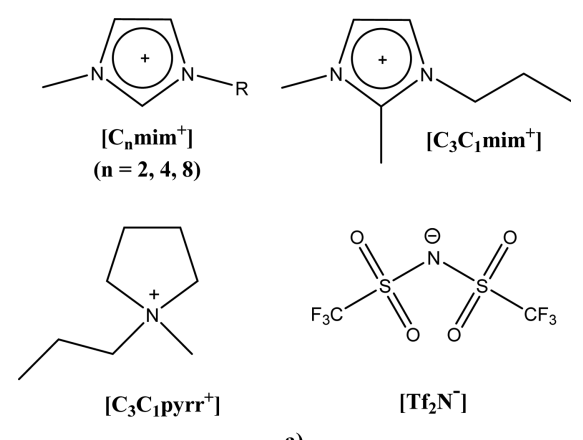

a)

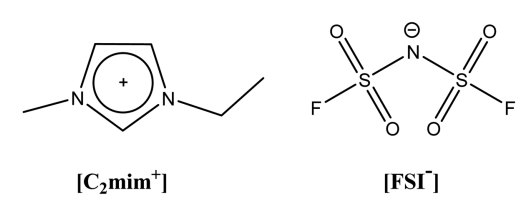

b)

Figure 1. Chemical structure of ionic liquid cations and anions used in the present work: (a) $\left[\mathrm{Tf}_{2} \mathrm{~N}\right]$-based ILs; (b) $\left[\mathrm{C}_{2} \mathrm{mim}\right][\mathrm{FSI}]$. Parameter $n$ gives the number of carbon atoms in alkyl chain $\mathrm{R}$.

istics are given in Table 1 and sorted in the order of increasing viscosities. Deionized water from a PURELAB flex purification system (ELGA) with a resistivity of $18.2 \mathrm{M} \Omega \mathrm{cm}$ was used for solution preparations and dilutions.

Thallium Radionuclide. Carrier-free ${ }^{201} \mathrm{Tl}$ (half-life $3.04 \mathrm{~d}$, $70.8 \mathrm{keV} \gamma$-ray, $46 \%$ intensity) medical radioisotope $(\sim 6 \mathrm{mCi})$ was purchased from Mallinckrodt (St. Louis, Missouri, USA). The production method is ${ }^{203} \mathrm{Tl}(\mathrm{p}, 3 \mathrm{n}){ }^{201} \mathrm{~Pb} \rightarrow{ }^{201} \mathrm{Tl}$. Thallium chloride is in $0.9 \%(\mathrm{w} / \mathrm{v})$ sodium chloride and preserved with $0.9 \%(\mathrm{v} / \mathrm{v})$ benzyl alcohol. The ${ }^{201} \mathrm{Tl}$ concentration per sample in our experiments after multistep dilution was below $1 \times 10^{-11}$ M. This amount of ${ }^{201} \mathrm{Tl}$ provided an optimal level of the activity for $\gamma$-counting of each phase after extraction.

Thallium Oxidation State. The thallium oxidation state in the ${ }^{201} \mathrm{Tl}$ stock solution was assigned to +1 according to our previous work. ${ }^{42}$ Bromine and chlorine water were utilized in order to maintain the highest thallium oxidation state. Two stock aqueous solutions of $\sim 10^{-3} \mathrm{M}$ of stable thallium were also prepared by dissolving a given quantity of $\mathrm{Tl}$ (III) chloride hydrate salt in 0.1 and $0.5 \mathrm{M} \mathrm{HCl}$. The predominant oxidation state of $\mathrm{Tl}$ in the stock solution was determined by a batch cation exchange technique based on previously reported data. ${ }^{59}$ The stable thallium stock solution $(10 \mathrm{~mL})$ in $0.1 \mathrm{M} \mathrm{HCl}$ was placed in contact with $4 \mathrm{~g}$ of AG 50Wx8 resin (200-400 mesh) for $2 \mathrm{~h}$ for $\mathrm{Tl}(\mathrm{I})$ sorption. It was shown that approximately $10 \%$ of thallium was adsorbed on the resin, meaning that approximately $90 \%$ of thallium was in the +3 oxidation state in the stock solution. Another stock solution in $0.5 \mathrm{M} \mathrm{HCl}$ was used for investigation of the effect of stable thallium concentration on metal extraction in the presence of ${ }^{201} \mathrm{Tl}$ and chlorine water.

Extraction Sample Preparation and Technical Procedure. The distribution of $\mathrm{Tl}$ was measured by a standard liquid-liquid extraction technique. Typically, equal volumes of organic and aqueous phases were used $(0.5 \mathrm{~mL}$ each, $1: 1$ phase ratio). The aqueous phases were obtained by dilution of concentrated $\mathrm{HCl}$. After both phases were placed into a test 
Table 1. Properties of Ionic Liquids Applied in This Study ${ }^{a}$

$\begin{array}{lcccccc}\text { ionic liquid } & \text { molar mass, } \mathrm{g} / \mathrm{mol} & \text { melting point, }{ }^{\circ} \mathrm{C} & \text { density, } \mathrm{g} / \mathrm{mL} & \text { viscosity, } \mathrm{cP} & \text { solubility in } \mathrm{H}_{2} \mathrm{O}, \mathrm{g} / \mathrm{L} & \text { cation hydrophobicity, log } k_{0, \mathrm{c}} \\ {\left[\mathrm{C}_{2} \mathrm{mim}\right][\mathrm{FSI}]} & 291.30 & -13 & 1.39 & 24.5 & 26.7 \pm 2.7^{c} & 0.22 \\ {\left[\mathrm{C}_{2} \mathrm{mim}\right]\left[\mathrm{Tf}_{2} \mathrm{~N}\right]} & 391.31 & -16 & 1.52 & 35.55 & 18.8 \pm 1.1 & 0.22 \\ {\left[\mathrm{C}_{4} \mathrm{mim}\right]\left[\mathrm{Tf}_{2} \mathrm{~N}\right]} & 419.36 & -4 & 1.43 & 61.14 & 6.6 \pm 0.4 & 0.67 \\ {\left[\mathrm{C}_{3} \mathrm{C}_{1} \text { pyrr }\right]\left[\mathrm{Tf}_{2} \mathrm{~N}\right]} & 408.40 & +12 & 1.40 & 71.23 & 10.5 \pm 0.6^{c} & <.57^{c} \\ {\left[\mathrm{C}_{3} \mathrm{C}_{1} \text { mim }\right]\left[\mathrm{Tf}_{2} \mathrm{~N}\right]} & 419.36 & +15 & 1.40 & 78.4 & 6.8 \pm 0.4^{c} & - \\ {\left[\mathrm{C}_{8} \mathrm{mim}\right]\left[\mathrm{Tf}_{2} \mathrm{~N}\right]} & 475.47 & <+20^{b} & 1.32 & 104 & 0.73 \pm 0.05 & 1.8\end{array}$

${ }^{a}$ Molar masses, melting points, densities, and viscosities were obtained from the manufacturer. Solubility of ILs in water and hydrophobicities of IL cations are from literature, ${ }^{57,58}$ respectively. ${ }^{b}$ Estimation based on practical use. ${ }^{c}$ This work. ${ }^{d}$ Estimation based on the decrease of cation hydrophobicity in the order $\left[\mathrm{C}_{8} \mathrm{C}_{1}\right.$ pyrr $\left.^{+}\right]>\left[\mathrm{C}_{6} \mathrm{C}_{1}\right.$ pyrr $\left.^{+}\right]>\left[\mathrm{C}_{4} \mathrm{C}_{1}\right.$ pyrr $\left.{ }^{+}\right]$.

tube, an aliquot of the thallium stock solution was added to the top aqueous phase. If ${ }^{201} \mathrm{Tl}$ was used as a target metallic ion to extract, an aliquot of bromine or chlorine water was added in order to obtain $\mathrm{Tl}$ (III) in the solution. The biphasic system was shaken mechanically (VWR Signature digital vortex mixer) at $3000 \mathrm{rpm}$ for $5 \mathrm{~min}$ (unless stated otherwise) at room temperature and then separated by centrifuging at $4000 \mathrm{rpm}$ for $1 \mathrm{~min}$ (Eppendorf model 5702). Then, an aliquot was taken from each phase to determine the thallium concentration or activity.

The metal distribution ratio, $D$, was determined by the following equation:

$$
D=\frac{A_{\text {org }}}{A_{a q}} \frac{V_{a q}}{V_{\text {org }}} \quad \text { or } \quad D=\frac{C_{\text {org }}}{C_{a q}} \frac{V_{a q}}{V_{\text {org }}}
$$

where $A, C$, and $V$ represent thallium activity, thallium concentration, and volume of the solution, respectively. We use the org and aq subscripts to define metal species in the organic and aqueous phases, respectively.

A PerkinElmer automatic $\gamma$ counter with an $\mathrm{NaI}$ detector ${ }^{60}$ was used to determine the ${ }^{201} \mathrm{Tl}$ activity level in the samples using a procedure described previously. ${ }^{61}$ The stable $\mathrm{Tl}(\mathrm{III})$ concentration in the stock and work solutions was determined by inductively coupled plasma mass-spectroscopy (ICP-MS, Agilent 7500i) after dilution to a concentration suitable for measurements with 1 volume percent of hydrochloric acid solution, which contained $10 \mu \mathrm{g} / \mathrm{L}$ holmium (Ho) as an internal standard.

The procedure to determine the equilibrium concentration of ionic liquid ions, $\left[\mathrm{C}_{n} \mathrm{mim}^{+}\right]$with $n=2,4$, and 8 , $\left[\mathrm{C}_{3} \mathrm{C}_{1}\right.$ pyrr $\left.{ }^{+}\right]$, and $\left[\mathrm{Tf}_{2} \mathrm{~N}^{-}\right]$in the aqueous phase after extraction was described in detail in a previous publication. ${ }^{57}$

Only statistical errors in $\gamma$-ray counts were plotted, and systematic experimental errors are estimated to be at a level of $10 \%$. The experiments were generally repeated twice and some, especially with high $D$ values, were carried out in triplicate.

TI(III) Loading. The method of determining the maximum concentration of $\mathrm{Tl}(\mathrm{III})$ in the organic phase was as follows. Aliquots of stable $\mathrm{Tl}(\mathrm{III})$ stock solution in $0.5 \mathrm{M} \mathrm{HCl}$ were added to $\left[\mathrm{C}_{2} \mathrm{mim}\right]\left[\mathrm{Tf}_{2} \mathrm{~N}\right]$ organic phase to cover metal concentrations in the range from $1 \times 10^{-5}$ to $1 \times 10^{-1} \mathrm{M}$. Then, $25 \mu \mathrm{L}$ of saturated chlorine water was added and the aqueous phases were spiked with ${ }^{201} \mathrm{Tl}$. After extraction, the metal activity in each phase was measured.

Back-Extraction. After the ${ }^{201} \mathrm{Tl}$ forward extraction, an aliquot of the ionic liquid phase was placed in a plastic tube, and an equal volume of $10.2 \mathrm{M} \mathrm{HCl}$ was added (volume ratio $1: 1)$. Then, the same procedure as in the case of forward extraction was applied.

\section{RESULTS AND DISCUSSION}

The two stable oxidation states of thallium in solution are +1 and +3 , and these states are of interest in this study. It should be noted that the use of a radioactive thallium isotope $\left({ }^{201} \mathrm{Tl}\right)$ allows for measuring both extremely low and extremely high metal distribution ratios without additional modification of the experimental protocol. This approach allows one to use ultratrace concentrations of the metal and to significantly increase the detection sensitivity simultaneously.

$\mathrm{TI}(\mathrm{I})$ Extraction into Pure ILs. The imidazolium-based ionic liquids with different alkyl chain lengths, $\left[\mathrm{C}_{n} \mathrm{mim}\right]\left[\mathrm{Tf}_{2} \mathrm{~N}\right]$ $(n=2,4$, and 8$)$, were examined for $\mathrm{Tl}(\mathrm{I})$ extraction from aqueous $\mathrm{HCl}$ solutions. Figure 2 shows the decreasing trend for

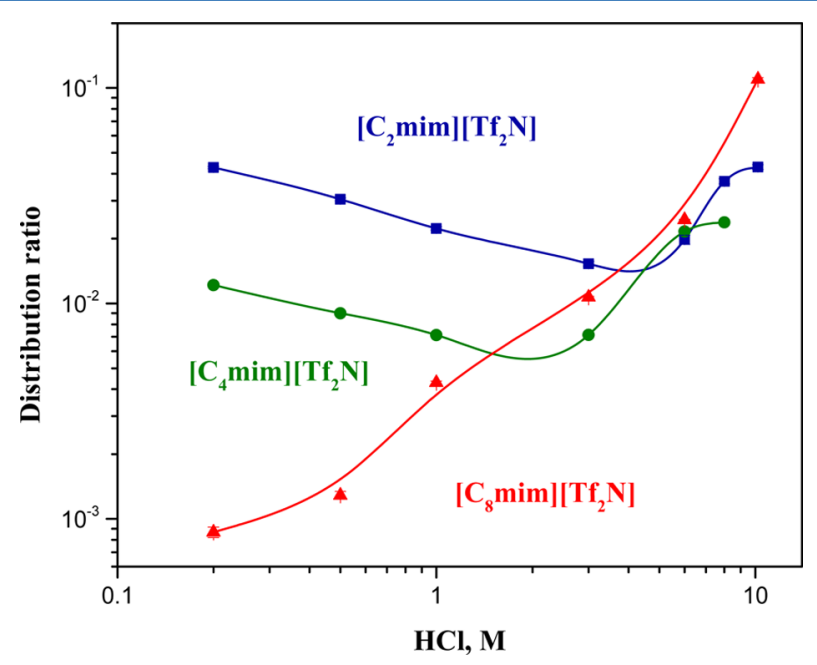

Figure 2. Effect of aqueous $\mathrm{HCl}$ concentration on $\mathrm{Tl}(\mathrm{I})$ extraction into $\left[\mathrm{C}_{n} \mathrm{mim}\right]\left[\mathrm{Tf}_{2} \mathrm{~N}\right](n=2,4$ and 8$)$ ionic liquids.

$\mathrm{Tl}(\mathrm{I})$ extraction into $\left[\mathrm{C}_{2} \operatorname{mim}\right]\left[\mathrm{Tf}_{2} \mathrm{~N}\right]$ and $\left[\mathrm{C}_{4} \mathrm{mim}\right]\left[\mathrm{Tf}_{2} \mathrm{~N}\right]$ ionic liquids at low aqueous $\mathrm{HCl}$ concentrations $([\mathrm{HCl}]<3$ $\mathrm{M})$. At a given aqueous $\mathrm{HCl}$ concentration, $D_{\mathrm{Tl}(\mathrm{I})}$ values decrease as the length of the aliphatic tail increases in the order $\left[\mathrm{C}_{2} \mathrm{mim}\right]\left[\mathrm{Tf}_{2} \mathrm{~N}\right]>\left[\mathrm{C}_{4} \mathrm{mim}\right]\left[\mathrm{Tf}_{2} \mathrm{~N}\right]>\left[\mathrm{C}_{8} \mathrm{mim}\right]\left[\mathrm{Tf}_{2} \mathrm{~N}\right]$. When $[\mathrm{HCl}] \geq 3 \mathrm{M}$ in the aqueous phase, similar trends of increasing $\mathrm{Tl}(\mathrm{I})$ extraction into $\left[\mathrm{C}_{n} \mathrm{mim}\right]\left[\mathrm{Tf}_{2} \mathrm{~N}\right](n=2,4$, and 8) with increasing acid concentration are observed.

The speciation of the metal ion in aqueous solution allows us to determine the mechanism of the extraction process. In the case of $\mathrm{Tl}(\mathrm{I})$, the predominant species in the diluted aqueous hydrochloric acid solutions is mainly $\mathrm{Tl}^{+} .62$ The high hydrophilicity of $\mathrm{Tl}^{+}$is unfavorable for its transfer into pure IL phase and results in a low efficiency for the extraction process. Nevertheless, the dependence of the $\mathrm{Tl}(\mathrm{I})$ extraction 
efficiency on the structure and composition of pure ILs can still be used to interpret our findings in the terms of the hydrophobicity/hydrophilicity of the ILs.

$\mathrm{Tl}(\mathrm{I})$ transfer into the IL phase at low aqueous acidities ( $<3 \mathrm{M} \mathrm{HCl}$ for $\left[\mathrm{C}_{2} \mathrm{mim}\right]\left[\mathrm{Tf}_{2} \mathrm{~N}\right]$ and $\left[\mathrm{C}_{4} \operatorname{mim}\right]\left[\mathrm{Tf}_{2} \mathrm{~N}\right]$ ) can be described by cation exchange between $\mathrm{Tl}^{+}$and IL cation:

$$
\left[\mathrm{Tl}^{+}\right]_{\mathrm{aq}}+\left[\mathrm{C}_{n} \mathrm{mim}^{+}\right]_{\mathrm{org}} \rightleftarrows\left[\mathrm{Tl}^{+}\right]_{\text {org }}+\left[\mathrm{C}_{n} \mathrm{mim}^{+}\right]_{\mathrm{aq}}(n=2 \text { and } 4)
$$

The hydrophobicity of imidazolium-based ILs, $\left[\mathrm{C}_{n} \operatorname{mim}\right]\left[\mathrm{Tf}_{2} \mathrm{~N}\right]$, with various alkyl chain lengths increases in the order $\left[\mathrm{C}_{2} \mathrm{mim}^{+}\right]<\left[\mathrm{C}_{4} \mathrm{mim}^{+}\right]<\left[\mathrm{C}_{8} \mathrm{mim}^{+}\right]$, and the solubility of these ILs in the aqueous phase decreases in the same order (see Table 1). As can be seen from Figure 2, the extraction efficiency of $\mathrm{Tl}(\mathrm{I})$ at low aqueous acidity decreases in this order, i.e., higher extraction of $\mathrm{Tl}(\mathrm{I})$ has been observed in the case of ILs with shorter alkyl chains. This is likely due to increased solubility of $\left[\mathrm{C}_{n} \mathrm{mim}^{+}\right](n=2$ and 4$)$ cations with shorter aliphatic chains in the aqueous phase, where the extraction of $\mathrm{Tl}^{+}$occurs according to eq $2 . \mathrm{Tl}(\mathrm{I})$ is probably also extracted with very small $D_{\mathrm{Tl}(\mathrm{I})}$ values from low $\mathrm{HCl}$ concentrations into the $\left[\mathrm{C}_{8} \mathrm{mim}\right]\left[\mathrm{Tf}_{2} \mathrm{~N}\right]$ ionic liquid via a cation exchange mechanism, but this was not studied in the current work.

The extraction of monovalent thallium from $>3 \mathrm{M} \mathrm{HCl}$ into $\left[\mathrm{C}_{n} \mathrm{mim}\right]\left[\mathrm{Tf}_{2} \mathrm{~N}\right](n=2,4$, and 8$)$ is nearly independent of the IL cation structure. This change in the $\mathrm{Tl}(\mathrm{I})$ extraction behavior most likely depends on the metal speciation in solution, which determines the dominant extraction mechanism. At high $\mathrm{HCl}$ concentration in the aqueous phase, $\mathrm{Tl}(\mathrm{I})$ likely forms an anionic complex such as $\mathrm{TlCl}_{2}{ }^{-}$and/or a neutral species such as $\mathrm{TlCl}^{62}$ Thus, $\mathrm{Tl}(\mathrm{I})$ extraction from the aqueous solution that caused the increase in $D_{\mathrm{Tl}(\mathrm{I})}$ for all three ILs possibly proceeds via anion exchange:

$$
\left[\mathrm{TlCl}_{2}^{-}\right]_{\mathrm{aq}}+\left[\mathrm{Tf}_{2} \mathrm{~N}^{-}\right]_{\mathrm{org}} \rightleftarrows\left[\mathrm{TlCl}_{2}^{-}\right]_{\mathrm{org}}+\left[\mathrm{Tf}_{2} \mathrm{~N}^{-}\right]_{\mathrm{aq}}
$$

Ion pair formation between $\mathrm{TlCl}_{2}^{-}$and IL cations, and/or extraction of neutral $\mathrm{TlCl}$ could also take place.

Figure 3 shows the extraction behaviors of two ionic liquids which have an identical cation, $\left[\mathrm{C}_{2} \mathrm{mim}^{+}\right]$, but have different anions, $\left[\mathrm{FSI}^{-}\right]$and $\left[\mathrm{Tf}_{2} \mathrm{~N}^{-}\right]$(see Figure 1 ). The $D_{\mathrm{Tl}(\mathrm{I})}$ values of $\left[\mathrm{C}_{2} \mathrm{mim}\right][\mathrm{FSI}]$ are slightly higher than those of

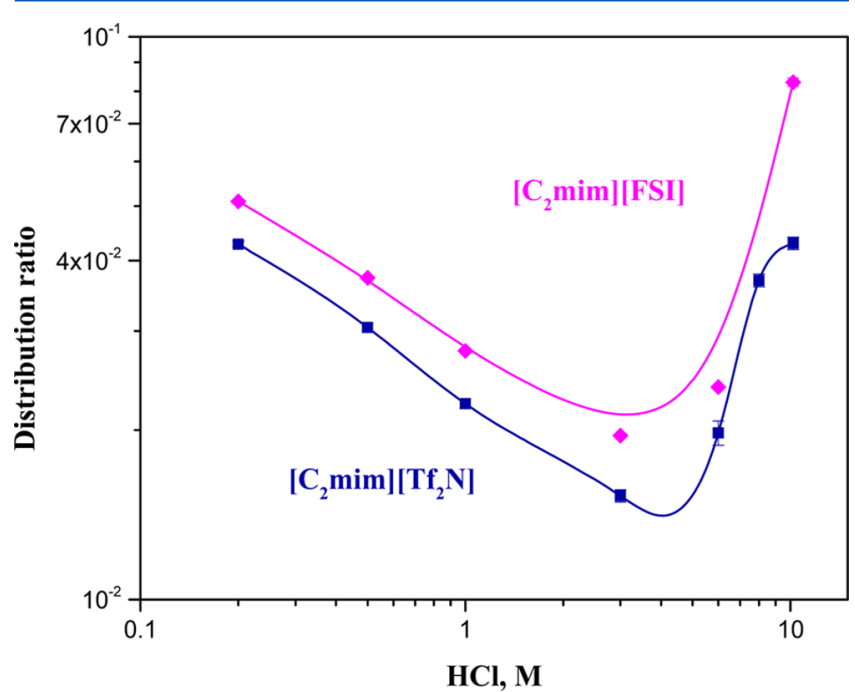

Figure 3. Extraction of $\mathrm{Tl}(\mathrm{I})$ from aqueous solutions of varying $\mathrm{HCl}$ concentration into $\left[\mathrm{C}_{2} \mathrm{mim}\right][\mathrm{FSI}]$ and $\left[\mathrm{C}_{2} \mathrm{mim}\right]\left[\mathrm{Tf}_{2} \mathrm{~N}\right]$ ionic liquids.
$\left[\mathrm{C}_{2} \mathrm{mim}\right]\left[\mathrm{Tf}_{2} \mathrm{~N}\right]$ for all $\mathrm{HCl}$ concentrations, although both curves decrease with increasing acid concentration for $\leq 3 \mathrm{M}$ $\mathrm{HCl}$ and increase with increasing acid concentration for $>3 \mathrm{M}$ $\mathrm{HCl}$. The $D_{\mathrm{Tl}(\mathrm{I})}$ values are below 0.1 in all cases. The data shown in Figure 3 suggest that cation exchange takes place in $\leq 3 \mathrm{M} \mathrm{HCl}$ according to eq 2 , and that anion exchange/ion pair formation of $\mathrm{TlCl}_{2}{ }^{-}$is favorable in $>3 \mathrm{M} \mathrm{HCl}$ according to eq 3 (although extraction of neutral $\mathrm{TlCl}$ complexes is also possible).

Figure 4 shows the effect of IL cation variation on the extraction of $\mathrm{Tl}(\mathrm{I})$ into the $\left[\mathrm{Tf}_{2} \mathrm{~N}\right]$ - and [FSI]-based ionic

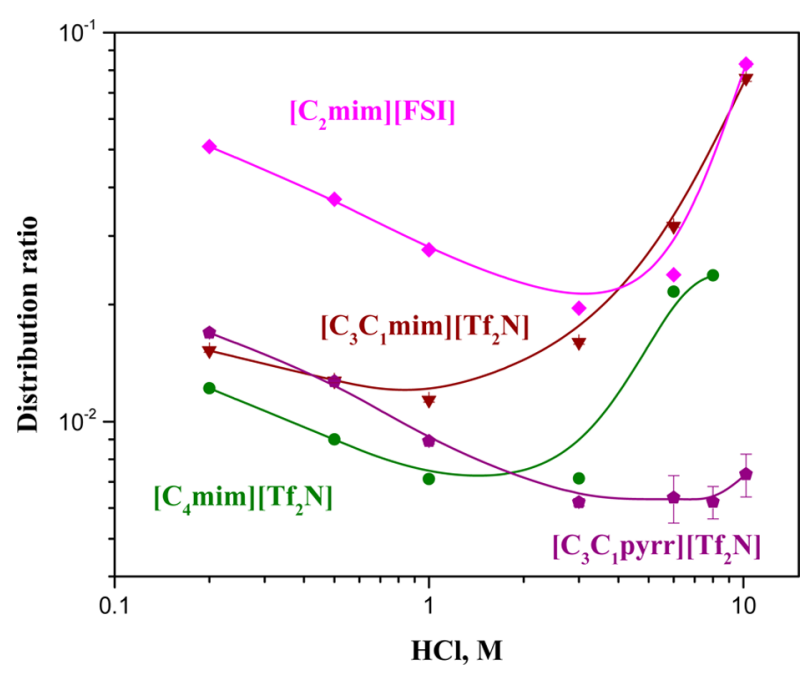

Figure 4. Extraction of $\mathrm{Tl}(\mathrm{I})$ from aqueous solutions of varying $\mathrm{HCl}$ concentration into $\left[\mathrm{C}_{3} \mathrm{C}_{1} \mathrm{mim}\right]\left[\mathrm{Tf}_{2} \mathrm{~N}\right],\left[\mathrm{C}_{4} \mathrm{mim}\right]\left[\mathrm{Tf}_{2} \mathrm{~N}\right]$, $\left[\mathrm{C}_{3} \mathrm{C}_{1}\right.$ pyrr $]\left[\mathrm{Tf}_{2} \mathrm{~N}\right]$, and $\left[\mathrm{C}_{2} \mathrm{mim}\right][\mathrm{FSI}]$.

liquids. It should be noted that in case of $\left[\mathrm{C}_{3} \mathrm{C}_{1} \mathrm{mim}\right]\left[\mathrm{Tf}_{2} \mathrm{~N}\right]$ and $\left[\mathrm{C}_{4} \mathrm{mim}\right]\left[\mathrm{Tf}_{2} \mathrm{~N}\right]$, the cation in both cases contains the same number of carbon atoms in its alkyl chain, however as shown in Figure 1, the structures of the IL cations are different. The longer aliphatic butyl $\left(-\mathrm{C}_{4} \mathrm{H}_{9}\right)$ group of the $\left[\mathrm{C}_{4} \mathrm{mim}\right]\left[\mathrm{Tf}_{2} \mathrm{~N}\right]$ ionic liquid was substituted by a propyl $\left(-\mathrm{C}_{3} \mathrm{H}_{7}\right)$ group, and one more methyl $\left(-\mathrm{CH}_{3}\right)$ group replaced an $\mathrm{H}$ atom on the imidazolium ring. It can be seen that the $D_{\mathrm{Tl}(\mathrm{I})}$ values are slightly higher in case of the $\left[\mathrm{C}_{3} \mathrm{C}_{1} \mathrm{mim}\right]\left[\mathrm{Tf}_{2} \mathrm{~N}\right]$ ionic liquid in comparison to those of $\left[\mathrm{C}_{4} \mathrm{mim}\right]\left[\mathrm{Tf}_{2} \mathrm{~N}\right]$. It should be noted that the structural changes between $\left[\mathrm{C}_{3} \mathrm{C}_{1} \mathrm{mim}^{+}\right]$and $\left[\mathrm{C}_{4} \mathrm{mim}^{+}\right]$result in less hydrophobicity and slightly improved extraction by the former. Figure 4 also allows for comparison of the extraction of $\mathrm{Tl}(\mathrm{I})$ into the imidazolium-based $\left[\mathrm{C}_{3} \mathrm{C}_{1} \mathrm{mim}\right]\left[\mathrm{Tf}_{2} \mathrm{~N}\right]$ and pyrrolidinium-based $\left[\mathrm{C}_{3} \mathrm{C}_{1}\right.$ pyrr $]\left[\mathrm{Tf}_{2} \mathrm{~N}\right]$ ionic liquids. Overall, the $D_{\mathrm{Tl}(\mathrm{I})}$ values are notably higher for $\left[\mathrm{C}_{3} \mathrm{C}_{1} \mathrm{mim}\right]\left[\mathrm{Tf}_{2} \mathrm{~N}\right]$ in $\geq 1 \mathrm{M} \mathrm{HCl}$. Distribution ratio values for the $\left[\mathrm{C}_{2} \mathrm{mim}\right][\mathrm{FSI}]$ ionic liquid are also shown in Figure 4 to demonstrate how the change in the anionic part of the ILs can affect the extraction.

The similar shape of the extraction curves described in this section (Figures 2, 3, and 4) and the similar low $D_{\mathrm{Tl}(\mathrm{I})}$ values indicate an identical extraction mechanism takes place for all considered $\mathrm{Tl}(\mathrm{I}) / \mathrm{HCl} / / \mathrm{IL}$ extraction systems regardless of the composition and structure of the ILs. At low acidities, the predominant extraction process is cationic exchange between metallic and IL cations, and at high $\mathrm{HCl}$ aqueous concentrations, the extraction of anionic and/or neutral $\mathrm{TlCl}$ species is preferable. Extraction curves of similar shape were described 
previously for many IL-based extraction systems, for example, U(VI) extraction with TBP dissolved in ILs. ${ }^{63,64}$ The highest extraction efficiency of $\mathrm{Tl}(\mathrm{I})$, especially in the $<3 \mathrm{M} \mathrm{HCl}$ region, was observed in the case of pure $\left[\mathrm{C}_{2} \mathrm{mim}\right][\mathrm{FSI}]$.

TI(III) Extraction into Pure ILs. In previous experiments on the speciation of $\mathrm{Tl}$ (III) in aqueous $\mathrm{HCl}$ solutions, $\mathrm{TlCl}_{4}{ }^{-}$is the dominant complex in low acid concentrations $\left(\log \beta_{4}=\right.$ $17.0){ }^{65}$ while the formation of multicharged negative species takes place in high acid concentrations. For example, $\mathrm{TlCl}_{5}{ }^{2-}$ $\left(K_{5}=2.15\right)^{65}$ and $\mathrm{TlCl}_{6}{ }^{3-}\left(K_{6}=1.80\right)^{65}$ have been reported. ${ }^{66}$ When bromide ions are introduced in the $\mathrm{HCl}$ solution, pure tetrabromide $^{67}$ and/or mixed halide complexes of $\mathrm{Tl}$ (III) might exist in solution; for example, $\log \beta_{4}$ for $\mathrm{TlBr}_{4}^{-}$is equal to 22.3. ${ }^{65}$

Effect of Concentration and Nature of the Oxidizing Agent. In this work, bromine and chlorine water were used as oxidizers of $\mathrm{Tl}(\mathrm{I})$. In order to check influence of these compounds' aqueous phase concentrations on the corresponding $\mathrm{Tl}(\mathrm{III})$ distribution ratio, $\left[\mathrm{C}_{n} \mathrm{mim}\right]\left[\mathrm{Tf}_{2} \mathrm{~N}\right](n=2,4$, and 8$)$ ILs were used to extract thallium from $1 \mathrm{M} \mathrm{HCl}$ with varying oxidizing agent concentration. Figure 5 shows that thallium

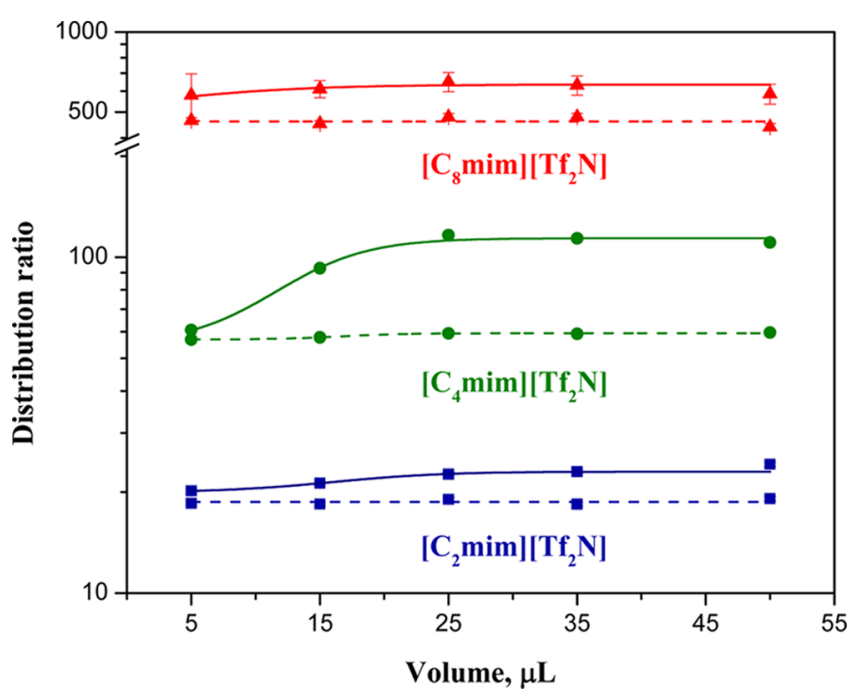

Figure 5. Distribution ratio of $\mathrm{Tl}(\mathrm{III})$ in $1 \mathrm{M} \mathrm{HCl}$ as a function of saturated bromine (solid lines) and chlorine (dashed lines) water content in the aqueous phase. Including oxidizer, the total volume of the aqueous phase was $500 \mu \mathrm{L}$ in each case.

extraction is independent of chlorine content in the range from 5 to $50 \mu \mathrm{L}$ of added saturated oxidizer solution. Constant distribution ratio values have been observed for each IL, and these results confirm the reproducibility of the data. However, the influence of bromine water concentration in each sample is significant, and the results clearly indicate that the $D_{\mathrm{Tl}(\mathrm{III})}$ values reach a plateau above $25 \mu \mathrm{L}$ of this oxidizer. Thus, in order to be sure that enough amounts of the oxidizer is contained in our samples, all the following trials were performed with $25 \mu \mathrm{L}$ of bromine and chlorine water. It should be noted that for longterm experiments or analyses, higher bromine water volumes per sample might be needed because of bromine degradation under UV light.

Figure 5 shows that thallium distribution ratios in $1 \mathrm{M} \mathrm{HCl}$ are lower in the presence of chlorine water than in the presence of bromine water. This is probably due to the fact that bromide complexes of thallium have a higher affinity for the ionic liquid phase (because of higher hydrophobicity) than those of chloride complexes. This hypothesis is supported by a previous report that notes the ability of anions to exchange with $\left[\mathrm{Tf}_{2} \mathrm{~N}^{-}\right]$ increases in the order $\mathrm{F}^{-}<\mathrm{Cl}^{-}<\mathrm{Br}^{-}<\mathrm{I}^{-}$. ${ }^{68}$ Thus, the extraction of $\mathrm{Tl}(\mathrm{III})$ complexes from $\mathrm{HBr}+\mathrm{Br}_{2}$ media is expected to result in higher $D_{\mathrm{Tl}(\mathrm{III})}$ values. Nevertheless, the current work was considered to be a continuation of our previous study, so we focused on thallium extraction from $\mathrm{HCl}$ $+\mathrm{Br}_{2}$ and $\mathrm{HCl}+\mathrm{Cl}_{2}$ aqueous solutions.

Kinetics. One of the most important aspects of solvent extraction is kinetics, and many parameters may affect this process. In our case, four different $\left[\mathrm{Tf}_{2} \mathrm{~N}\right]$-based ILs, namely $\left[\mathrm{C}_{n} \mathrm{mim}\right]\left[\mathrm{Tf}_{2} \mathrm{~N}\right](n=2,4$, and 8$)$ and $\left[\mathrm{C}_{3} \mathrm{C}_{1}\right.$ pyrr $]\left[\mathrm{Tf}_{2} \mathrm{~N}\right]$, have been evaluated in terms of how fast thallium in the presence of bromine water can be transferred into the organic phase. The main parameter considered here is the time when the two immiscible phases were vigorously mixed together, because this step significantly intensifies the extraction due to an increase in the surface area of the phases in contact. The biphasic system was stirred at $3000 \mathrm{rpm}$ for different time intervals in the range from 0.5 to $20 \mathrm{~min}$ at room temperature and then separated by centrifuging as stated above. It has been found (Figure 6) that

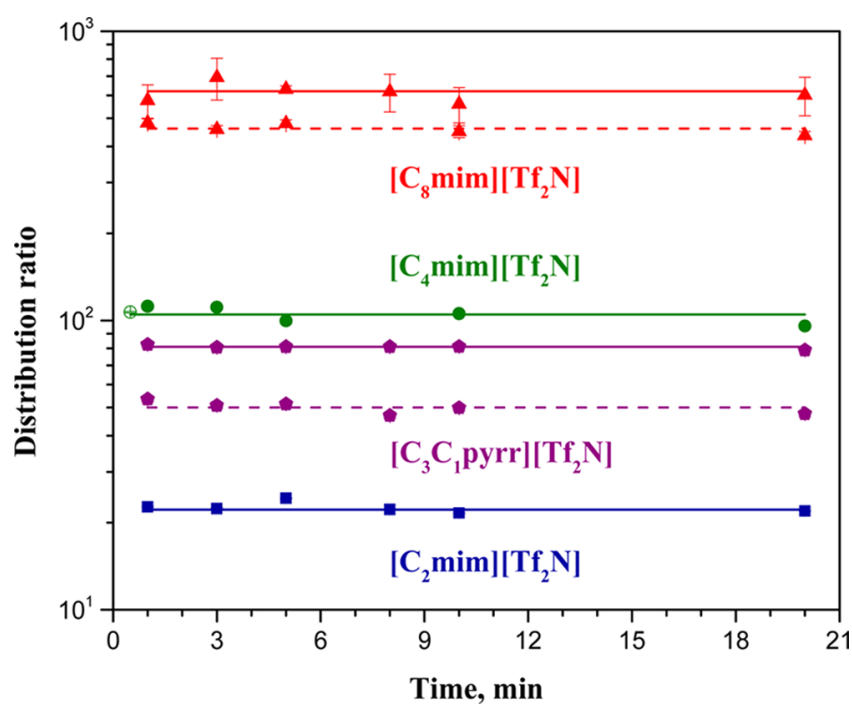

Figure 6. Kinetic study of $\mathrm{Tl}(\mathrm{III})$ extraction into various $\left[\mathrm{Tf}_{2} \mathrm{~N}\right]$-based ionic liquids from $1 \mathrm{M} \mathrm{HCl}$ with $25 \mu \mathrm{L}$ of bromine (solid lines) or chlorine (dashed lines) water as an oxidizer.

equilibrium is achieved in seconds. One additional experiment with $\left[\mathrm{C}_{4} \mathrm{mim}\right]\left[\mathrm{Tf}_{2} \mathrm{~N}\right]$ ionic liquid has been performed to study $\mathrm{Tl}(\mathrm{III})$ extraction when less intensive, manual shaking, was implemented for just $30 \mathrm{~s}$. The trivalent thallium distribution ratio was found to be consistent with the other data points. Also, two more sets of experiments were performed with $\left[\mathrm{C}_{8} \mathrm{mim}\right]\left[\mathrm{Tf}_{2} \mathrm{~N}\right]$ and $\left[\mathrm{C}_{3} \mathrm{C}_{1}\right.$ pyrr $]\left[\mathrm{Tf}_{2} \mathrm{~N}\right]$ ionic liquids when chlorine water instead of bromine water was used to oxidize $\mathrm{Tl}(\mathrm{I})$. The results again showed that equilibrium is reached very quickly. Thus, unexpected relatively fast extraction of $\mathrm{Tl}$ (III) into $\left[\mathrm{Tf}_{2} \mathrm{~N}\right]$-based ILs was observed. Nevertheless, $5 \mathrm{~min}$ shaking time was chosen for the remaining experiments based on experimental convenience. A systematic study of the kinetics of metal extraction with less than $1 \mathrm{~min}$ of shaking requires time-consuming automation of the experiments, because such factors as phase contact time and phase separation time are not negligible anymore. Also, the influence of alkyl chain length and IL structure plays a crucial role in determining the extraction 
efficiency, since it can be seen that the $D_{\mathrm{Tl}(\mathrm{III})}$ values are in a wide range from 20 to 700 . The surprisingly fast kinetics of trivalent thallium extraction is beneficial for analysis of both environmental and any other kind of samples.

Influence of Hydrochloric Acid Concentration and Effect of the IL Structure. On the basis of the two previous sections, we chose the optimal conditions for thallium extraction $(25 \mu \mathrm{L}$ of the oxidizer and $5 \mathrm{~min}$ of sample shaking). Next, we studied the influence of aqueous phase $\mathrm{HCl}$ concentration on metal extraction in the presence of bromine water, chlorine water and in the absence of any oxidizer. Figure 7 shows that the tendency of bromide-based $\mathrm{Tl}$ (III) complexes

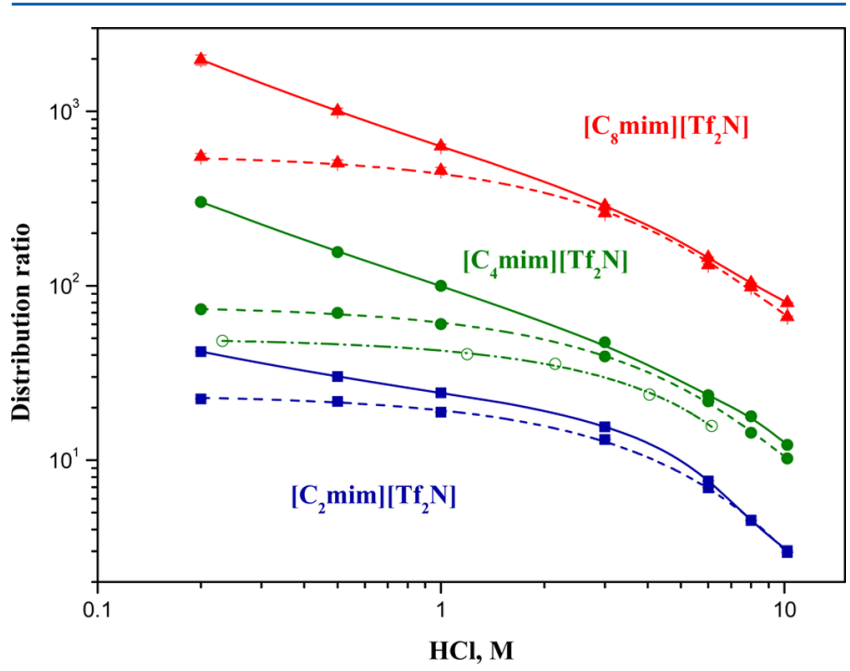

Figure 7. $\mathrm{Tl}(\mathrm{III})$ extraction from $\mathrm{HCl}$ aqueous solutions into $\left[\mathrm{C}_{n} \operatorname{mim}\right]\left[\mathrm{Tf}_{2} \mathrm{~N}\right]$ ionic liquids $(n=2,4$ and 8$)$. Solid and dashed lines with closed symbols are for bromine and chlorine water oxidized data, respectively. The dash dot line with open symbols is for no oxidizing agent.

to extract compared to chloride-based ones remains qualitatively the same over the entire acid concentration range, but the quantitative results are drastically different in the $<3 \mathrm{M} \mathrm{HCl}$ region.

The Tl(III) data with no oxidizing agent (dash dot line in Figure 7) show the lowest distribution ratio values over the entire $\mathrm{HCl}$ concentration range for the $\left[\mathrm{C}_{4} \mathrm{mim}\right]\left[\mathrm{Tf}_{2} \mathrm{~N}\right]$ ionic liquid. The shape of this curve is similar to that for chlorine water, due to the extraction of pure chloride complexes in both cases. Figure 7 shows that $\mathrm{Tl}$ (III) extraction in the absence of an oxidizer is $25-30 \%$ lower than that in the presence of chlorine water. This behavior is probably due to the oxidizer presence in the aqueous phase, but this effect was not studied in detail in this work.

We also studied the influence of the length of the alkyl chain substituent to the imidazolium ring on $\mathrm{Tl}$ (III) extraction from $\mathrm{HCl}$ media. Figure 7 also depicts data for ionic liquids with the same anion and 3 alkyl group substituents varying from ethyl to octyl, and greater $D_{\mathrm{Tl}(\mathrm{III})}$ values have been observed for ionic liquids with longer aliphatic chains. These results are analogous to those found for $\mathrm{Hg}(\mathrm{II})$ and $\mathrm{Pu}(\mathrm{IV})$ extraction into other imidazolium-based ILs, which showed a strong dependence on alkyl chain length. ${ }^{50,55,56}$ Also, the current work for $\mathrm{Tl}(\mathrm{III}) /(0.2$ $\mathrm{M} \mathrm{HCl}+0.01 \mathrm{M} \mathrm{Br} 2) / /\left[\mathrm{C}_{8} \mathrm{mim}\right]\left[\mathrm{Tf}_{2} \mathrm{~N}\right]$ and previously reported $\mathrm{Tl}(\mathrm{III}) /\left(0.2 \mathrm{M} \mathrm{HCl}+0.01 \mathrm{M} \mathrm{Br}_{2}\right) / / 30 \% \mathrm{TBP} /$ toluene $^{42}$ systems show comparable distribution ratios of 1970 \pm 130 and $1610 \pm 320$, respectively.
The Tl(III) extraction from aqueous hydrochloric acid solutions into $\left[\mathrm{C}_{n} \mathrm{mim}\right]\left[\mathrm{Tf}_{2} \mathrm{~N}\right]$ ionic liquids $(n=2,4$, and 8$)$ increases in the order $\left[\mathrm{C}_{2} \mathrm{mim}\right]\left[\mathrm{Tf}_{2} \mathrm{~N}\right]<\left[\mathrm{C}_{4} \mathrm{mim}\right]\left[\mathrm{Tf}_{2} \mathrm{~N}\right]<$ $\left[\mathrm{C}_{8} \mathrm{mim}\right]\left[\mathrm{Tf}_{2} \mathrm{~N}\right]$ (see Figure 7 ), and the hydrophobicity of the corresponding cations increases in the same order (see Table 1). Thus, imidazolium-based ionic liquids, $\left[\mathrm{C}_{n} \mathrm{mim}\right]\left[\mathrm{Tf}_{2} \mathrm{~N}\right]$, with a long aliphatic tail $(n \geq 8)$ might be utilized to extract $\mathrm{Tl}(\mathrm{III})$ into the organic phase from low $\mathrm{HCl}$ concentration with $D_{\mathrm{Tl}(\mathrm{III})} \geq 10^{3}$.

Figure 8 shows the effect of different IL anion structures on $\mathrm{Tl}(\mathrm{III})$ extraction efficiency. Higher $D_{\mathrm{Tl}(\mathrm{III})}$ values were found

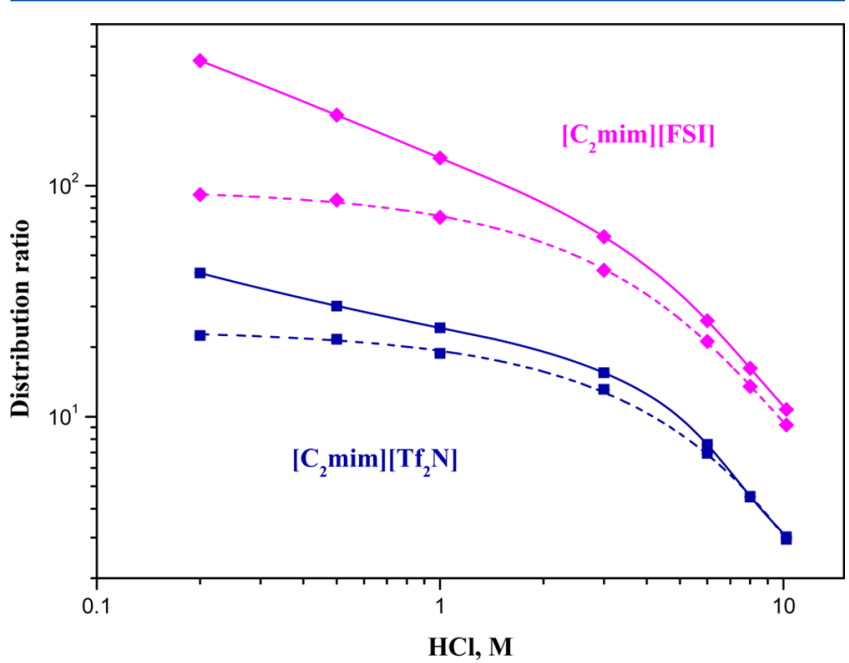

Figure 8. $\mathrm{Tl}(\mathrm{III})$ extraction from $\mathrm{HCl}$ media into the $\left[\mathrm{C}_{2} \mathrm{mim}\right]\left[\mathrm{Tf}_{2} \mathrm{~N}\right]$ and $\left[\mathrm{C}_{2} \mathrm{mim}\right][\mathrm{FSI}]$ ionic liquids. Solid and dashed lines include $25 \mu \mathrm{L}$ of bromine or chlorine water, respectively, as oxidizing agents.

for $\left[\mathrm{C}_{2} \mathrm{mim}\right][\mathrm{FSI}]$ than for $\left[\mathrm{C}_{2} \mathrm{mim}\right]\left[\mathrm{Tf}_{2} \mathrm{~N}\right]$ in the acid range from 0.2 to $10.2 \mathrm{M} \mathrm{HCl}$. The general trends in the data where thallium was oxidized by chlorine or bromine water, are the same as described above. It can be seen that there is no influence of IL structure on the shape of extraction curves. In all considered cases, $D_{\mathrm{Tl}(\mathrm{III})}$ decreases with increasing $\mathrm{HCl}$ concentration, and more steeply in the $>3 \mathrm{M} \mathrm{HCl}$ region.

Figure 9 shows the extraction of $\mathrm{Tl}(\mathrm{III})$ into various ionic liquids, and it is convenient to compare data grouped in pairs. One pair is $\left[\mathrm{C}_{4} \mathrm{mim}\right]\left[\mathrm{Tf}_{2} \mathrm{~N}\right]$ and $\left[\mathrm{C}_{3} \mathrm{C}_{1} \mathrm{mim}\right]\left[\mathrm{Tf}_{2} \mathrm{~N}\right]$, which have identical molecular weights and an identical anionic part. The $\left[\mathrm{C}_{4} \mathrm{mim}\right]\left[\mathrm{Tf}_{2} \mathrm{~N}\right] D_{\mathrm{Tl}(\mathrm{III})}$ values are lower than those of $\left[\mathrm{C}_{3} \mathrm{C}_{1} \mathrm{mim}\right]\left[\mathrm{Tf}_{2} \mathrm{~N}\right]$, which is probably due to the lengthening of the alkyl side chain and the removal of an acidic proton from the ring in the case of $\left[\mathrm{C}_{3} \mathrm{C}_{1} \mathrm{mim}^{+}\right]$. The solubility in water of these two ionic liquids is the same within error (see Table 1), but we are unable to attribute the change in $D_{\mathrm{Tl}(\mathrm{III})}$ values to the influence of the acidic proton without a further systematic study of the influence of the number of substituent chains to the imidazolium ring. The next pair is $\left[\mathrm{C}_{3} \mathrm{C}_{1} \mathrm{mim}\right]\left[\mathrm{Tf}_{2} \mathrm{~N}\right]$ and $\left[\mathrm{C}_{3} \mathrm{C}_{1}\right.$ pyrr $]\left[\mathrm{Tf}_{2} \mathrm{~N}\right]$. The anionic components and total number of carbons are identical (except the alkyl chain position), but the imidazolium ring is replaced by pyrrolidinium one. It should be noted that the $\left[\mathrm{C}_{3} \mathrm{C}_{1}\right.$ pyrr $]\left[\mathrm{Tf}_{2} \mathrm{~N}\right]$ data show the lowest values among the group of four ILs. $\left[\mathrm{C}_{2} \mathrm{mim}\right][\mathrm{FSI}]$ data are shown in Figure 9 for comparison with $\left[\mathrm{C}_{4} \mathrm{mim}\right]\left[\mathrm{Tf}_{2} \mathrm{~N}\right]$. The $\left[\mathrm{C}_{4} \mathrm{mim}\right]\left[\mathrm{Tf}_{2} \mathrm{~N}\right]$ data are slightly below those of $\left[\mathrm{C}_{2} \mathrm{mim}\right][\mathrm{FSI}]$ for low $\mathrm{HCl}$ concentrations, but they are comparable in $\geq 6 \mathrm{M}$ HCl. Generally, all four ILs shown in Figure 9 are effective 


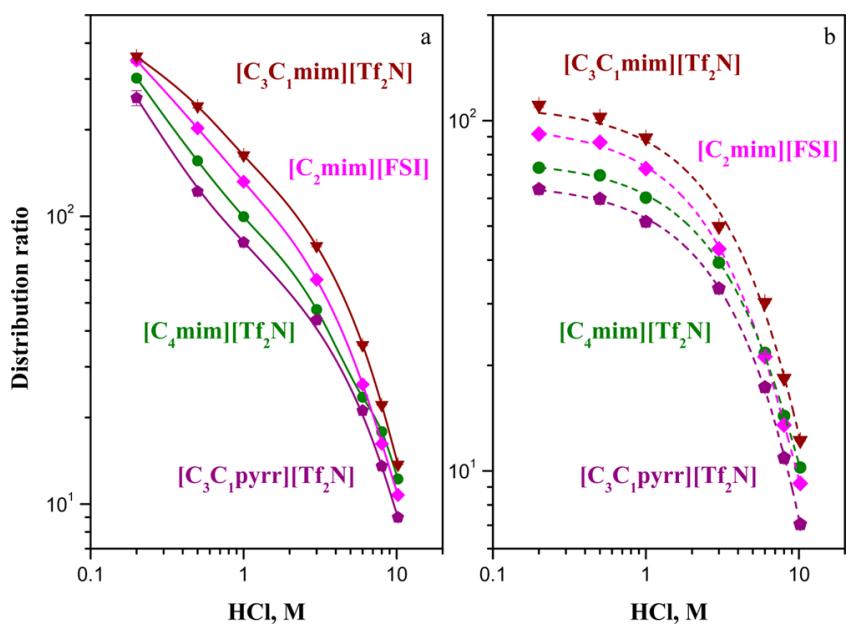

Figure 9. $\mathrm{Tl}(\mathrm{III})$ extraction from $\mathrm{HCl}$ aqueous solutions into different ionic liquids: (a) data with bromine water; (b) data with chlorine water.

extracting solvents and might be potentially applied for $\mathrm{Tl}(\mathrm{III})$ isolation from $\mathrm{HCl}$ media. It also must be noted that ILs are slightly soluble in aqueous solution, especially in highly acidic media, and this results in contamination of the aqueous phase by IL ions and partial loss of costly ionic solvent. One possible way to minimize this drawback is to use moderate acidities and/or highly hydrophobic (less soluble) ILs. For example, the $\left[\mathrm{C}_{8} \mathrm{mim}\right]\left[\mathrm{Tf}_{2} \mathrm{~N}\right]$ ionic liquid seems to be the most appropriate solvent according to its low solubility in water, but this one is very viscous and expensive as compared to $\left[\mathrm{C}_{4} \mathrm{mim}\right]\left[\mathrm{Tf}_{2} \mathrm{~N}\right]$. On the other hand, the $\left[\mathrm{C}_{2} \mathrm{mim}\right][\mathrm{FSI}]$ ionic liquid might be considered as more preferable from a practical point of view due to having the lowest viscosity (see Table 1 ), which makes work with this IL easier. Thus, a compromise between extraction efficiency, chemical conditions, technical aspects, and IL cost should be found for each particular extraction system.

It can be seen in Figure 9 that extraction with shorter alkyl chains on the imidazolium ring can be compensated by a less hydrophobic anion such as $\left[\mathrm{FSI}^{-}\right]$compared to $\left[\mathrm{Tf}_{2} \mathrm{~N}^{-}\right]$. The predominant $\mathrm{Tl}(\mathrm{III})$ species in the $\mathrm{HCl}$ aqueous solution is $\mathrm{TlX}_{4}^{-}$(where $\mathrm{X}=\mathrm{Cl}^{-}$and/or $\left.\mathrm{Br}^{-}\right)^{65-67}$ as discussed above. This suggests that the extraction mechanism (discussed in detail below) is an anion exchange reaction between $\mathrm{TlCl}_{4}{ }^{-}$ anionic complexes in the aqueous phase and IL anions in the organic phase, and/or ion pair formation in the aqueous phase between thallium species and IL cations.

If we summarize the results of all ionic liquids in this work, then the ability of the six ionic liquids considered to extract $\mathrm{Tl}(\mathrm{III})$ increases in the order $\left[\mathrm{C}_{2} \mathrm{mim}\right]\left[\mathrm{Tf}_{2} \mathrm{~N}\right]<$ $\left[\mathrm{C}_{3} \mathrm{C}_{1}\right.$ pyrr $]\left[\mathrm{Tf}_{2} \mathrm{~N}\right]<\left[\mathrm{C}_{4} \mathrm{mim}\right]\left[\mathrm{Tf}_{2} \mathrm{~N}\right]<\left[\mathrm{C}_{2} \mathrm{mim}\right][\mathrm{FSI}]<$ $\left[\mathrm{C}_{3} \mathrm{C}_{1} \mathrm{mim}\right]\left[\mathrm{Tf}_{2} \mathrm{~N}\right]<\left[\mathrm{C}_{8} \mathrm{mim}\right]\left[\mathrm{Tf}_{2} \mathrm{~N}\right]$. The solubility of $\left[\mathrm{Tf}_{2} \mathrm{~N}^{-}\right]$-based ionic liquids in water decreases in the same order (see Table 1). It should be noted that the $\left[\mathrm{Tf}_{2} \mathrm{~N}^{-}\right]$-anion is more hydrophobic than $\left[\mathrm{FSI}^{-}\right]$, because the former one contains six fluorine atoms versus two fluorine atoms in the latter (see Figure 1). Greater hydrophilicity can be expected due to the lower fluorine content in the molecule, and this explains the high solubility of $\left[\mathrm{C}_{2} \mathrm{mim}\right][\mathrm{FSI}]$. Nevertheless, the extraction mechanism is still the same and some insights to this process are given below.
Theoretical Extraction into an Ionic Liquid. Generally, the distribution of any metallic species between two immiscible phases, i.e., IL and aqueous solution, should be described in terms of ions transferred because ionic liquids are known to favor the extraction of charged complexes. ${ }^{33,54,69}$ This extraction behavior is completely different from molecular organic solvents, which are electrically neutral media and favor the extraction of neutral complexes.

In ionic liquid-based extraction of negatively charged complexes, one of the possible mechanisms is the anion exchange between an anionic species in the aqueous phase $\left(\left[\mathrm{S}^{z-}\right]_{\mathrm{aq}}\right.$, where $z$ is the charge of the species of interest) and an anion of the ionic liquid $\left(\left[\mathrm{A}^{-}\right]_{\text {org }}\right)$ :

$$
z\left[\mathrm{~A}^{-}\right]_{\mathrm{org}}+\left[\mathrm{S}^{z-}\right]_{\mathrm{aq}} \rightleftarrows\left[\mathrm{S}^{z-}\right]_{\mathrm{org}}+z\left[\mathrm{~A}^{-}\right]_{\mathrm{aq}}
$$

Another possible extraction mechanism is the formation of ion pair complexes. The generic equations to estimate extraction constants and proposed mechanisms of ion pairing can be found in previous reports. ${ }^{70-73}$ This process occurs between species of interest and counterions of the ionic liquid dissolved in the aqueous phase $\left(\left[\mathrm{C}^{+}\right]_{\mathrm{aq}}\right)$, followed by transfer into the IL phase. It can be described for anionic solutes as

$$
z\left[\mathrm{C}^{+}\right]_{\mathrm{aq}}+\left[\mathrm{S}^{z-}\right]_{\mathrm{aq}} \rightleftarrows z\left[\mathrm{C}^{+}\right]_{\mathrm{org}}+\left[\mathrm{S}^{z-}\right]_{\mathrm{org}}
$$

The solute transfer process into the IL phase is affected with the distribution of IL constituent ions between the two immiscible phases:

$$
\left[\mathrm{C}^{+}\right]_{\text {org }}+\left[\mathrm{A}^{-}\right]_{\mathrm{org}} \rightleftarrows\left[\mathrm{C}^{+}\right]_{\mathrm{aq}}+\left[\mathrm{A}^{-}\right]_{\mathrm{aq}}
$$

Thus, the equations to describe the process of solute transfer based on charge balance is

$$
\left[\mathrm{A}^{-}\right]_{\mathrm{aq}}-\left[\mathrm{C}^{+}\right]_{\mathrm{aq}}=z\left(\left[\mathrm{~S}^{z-}\right]_{\mathrm{aq}, \text { unit }}-\left[\mathrm{S}^{z-}\right]_{\mathrm{aq}}\right)=z \Delta\left[\mathrm{S}^{z-}\right]_{\mathrm{aq}}
$$

where "init" indicates the initial concentration of the species in the aqueous phase. The equilibrium constants for the ion exchange extraction mechanism $\left(K_{I E}\right.$, eq 8$)$, ion pair extraction $\left(K_{I P}\right.$, eq 9$)$, and the solubility product of the IL $\left(K_{s p}\right.$, eq 10$)$ are defined as

$$
\begin{aligned}
& K_{I E}=D_{S^{z-}}\left[\mathrm{A}^{-}\right]_{a q}{ }^{z} \\
& K_{I P}=D_{\mathrm{S}^{z-}}\left[\mathrm{C}^{+}\right]_{a q}{ }^{-z} \\
& K_{s p}=\left[\mathrm{C}^{+}\right]_{a q}\left[\mathrm{~A}^{-}\right]_{a q} \\
& K_{s p}{ }^{z}=K_{I E} K_{I P}^{-1}
\end{aligned}
$$

Combining eqs 7 and 10 leads to a quadratic equation in $\left[\mathrm{A}^{-}\right]_{\mathrm{aq}}$ :

$$
K_{s p}=\left(\left[\mathrm{A}^{-}\right]_{a q}-z \Delta\left[\mathrm{S}^{z-}\right]_{a q}\right)\left[\mathrm{A}^{-}\right]_{a q}
$$

Substituting the solution of this equation into eq 8 gives the following result:

$$
K_{I E}=D_{S^{z}}\left(\frac{z \Delta\left[S^{z-}\right]_{a q}+\left(z^{2} \Delta\left[S^{z-}\right]_{a q}{ }^{2}+4 K_{s p}\right)^{0.5}}{2}\right)^{z}
$$

The sign before the radical must be positive in order to eliminate nonphysical values of $K_{\mathrm{IE}}$. An analogous derivation might be done for $K_{\mathrm{IP}}$ or any cation extraction. Thus, the function $D_{S}=f\left(\Delta\left[S^{z \pm}\right]_{\mathrm{aq}}\right)$ describes the experimental data on the extraction of solutes from the aqueous phase into the ionic 
liquid phase. This function is not linear and the experimental nonlinearity is easily observed if the concentration of the extracted ion of interest is varied over a wide range. In the limit of infinite $\Delta\left[S^{z \pm}\right]_{\text {aq }}$, eq 13 collapses to

$$
\log D_{\infty}=\log K_{\mathrm{IE}}-z \log z-z \log \Delta\left[\mathrm{S}^{z \pm}\right]_{\mathrm{aq}}
$$

where $D_{\infty}$ is the distribution ratio for the theoretical infinitely concentrated $\Delta\left[S^{z \pm}\right]_{\mathrm{aq}}$. On a plot of $D$ versus $\Delta\left[\mathrm{S}^{z \pm}\right]_{\mathrm{aq}}$, the slope of the asymptote as $\Delta\left[\mathrm{S}^{z \pm}\right]_{\mathrm{aq}} \rightarrow \infty$ will be always negative regardless of whether cations or anions of interest are extracted. The parameter $z$ of the linear function given in eq 14 provides information on the number of cations or anions of the ionic liquid required to compensate the charge of the extracted ion. The value of $z$ is discussed in the next section.

It must be mentioned that the mathematical model considered above is correct only in the absence of $\mathrm{H}^{+}$-ions in the aqueous phase. In case of acidic aqueous solution, protonation of $\left[\mathrm{Tf}_{2} \mathrm{~N}^{-}\right]$anions must be taken into account and can be described as

$$
[\mathrm{HA}]_{\mathrm{aq}} \rightleftarrows\left[\mathrm{H}^{+}\right]_{\mathrm{aq}}+\left[\mathrm{A}^{-}\right]_{\mathrm{aq}}
$$

where the equilibrium concentrations of $\mathrm{H}\left[\mathrm{Tf}_{2} \mathrm{~N}\right]$ acid, protons, and $\left[\mathrm{Tf}_{2} \mathrm{~N}^{-}\right]$anions are represented as $[\mathrm{HA}]_{\mathrm{aq}}$, $\left[\mathrm{H}^{+}\right]_{\mathrm{aq}}$, and $\left[\mathrm{A}^{-}\right]_{\mathrm{aq}}$, respectively. The $\mathrm{H}\left[\mathrm{Tf}_{2} \mathrm{~N}\right]$ acid dissociation constant, $K_{a}$ is defined as

$$
K_{a}=\left[\mathrm{H}^{+}\right]\left[\mathrm{A}^{-}\right][\mathrm{HA}]^{-1}
$$

and was found to be $0.70 \pm 0.04 \mathrm{~mol} \mathrm{dm}{ }^{-3} \cdot{ }^{73}$ Therefore, eqs 8 and 10 must be modified due to the simultaneous presence of $\left[\mathrm{A}^{-}\right]_{\mathrm{aq}}$ and $[\mathrm{HA}]_{\mathrm{aq}}$ in the aqueous phase, and are defined as

$$
\begin{aligned}
& K_{I E}^{\prime}=D_{\mathrm{S}^{z-}}\left[\mathrm{A}^{-}\right]_{a q}^{z}\left(1+\left[\mathrm{H}^{+}\right]_{a q} K_{z}^{-1}\right)^{z} \\
& K_{s p}^{\prime}=\left[\mathrm{C}^{+}\right]_{a q}\left[\mathrm{~A}^{-}\right]_{a q}\left(1+\left[\mathrm{H}^{+}\right]_{a q} K_{a}^{-1}\right)
\end{aligned}
$$

where $\left[\mathrm{A}^{-}\right]_{a q}+[\mathrm{HA}]_{a q}=\left[\mathrm{A}^{-}\right]_{a q}\left(1+\left[\mathrm{H}^{+}\right]_{a q} K_{a}^{-1}\right)$.

$A$ widely used method to obtain more insight into the extraction mechanism is the introduction into the aqueous phase of a salt which has a common cation or anion with the ionic liquid under investigation, for example $\mathrm{Li}\left[\mathrm{Tf}_{2} \mathrm{~N}\right]$ for $\left[\mathrm{Tf}_{2} \mathrm{~N}\right]$-based ILs or $\left[\mathrm{C}_{10} \mathrm{mim}\right] \mathrm{Cl}$ for imidazolium-based ILs. ${ }^{56,74}$ The choice of corresponding compound depends on whether the anionic or cationic species of interest are expected to be predominant under the given chemical conditions. This approach allows one to determine the charge of the extracted ion and helps in the interpretation of extraction processes. The charge balance for the acidic aqueous phase before and after extraction when $\mathrm{Li}\left[\mathrm{Tf}_{2} \mathrm{~N}\right]$ is added to the aqueous phase (discussed below) can be defined as follows.

Before extraction:

$$
\left[\mathrm{Li}^{+}\right]_{\mathrm{aq}, \text { init }}+\left[\mathrm{H}^{+}\right]_{\mathrm{aq}, \text { init }}=\left[\mathrm{Tf}_{2} \mathrm{~N}^{-}\right]_{\mathrm{aq}, \text { init }}+\left[\mathrm{Cl}^{-}\right]_{\mathrm{aq}, \text { init }}+z\left[\mathrm{~S}^{z-}\right]_{\mathrm{aq}, \text { init }}
$$

After extraction:

$$
\left[\mathrm{Li}^{+}\right]_{\mathrm{aq}}+\left[\mathrm{H}^{+}\right]_{\mathrm{aq}}+\left[\mathrm{C}^{+}\right]_{\mathrm{aq}}=\left[\mathrm{Tf}_{2} \mathrm{~N}^{-}\right]_{\mathrm{aq}, \text { total }}+\left[\mathrm{Cl}^{-}\right]_{\mathrm{aq}}+z\left[\mathrm{~S}^{\mathrm{z}-}\right]_{\mathrm{aq}}
$$

It was experimentally confirmed that $\mathrm{Li}^{+}, \mathrm{H}^{+}$, and $\mathrm{Cl}^{-}$were not detectably extracted into the IL phase from up to $5 \mathrm{M} \mathrm{HCl}$, which is in agreement with the results of other researchers. $^{57,73,75}$ Thus, $\left[\mathrm{Li}^{+}\right]_{\mathrm{aq} \text {, init }}=\left[\mathrm{Li}^{+}\right]_{\mathrm{aq}},\left[\mathrm{H}^{+}\right]_{\mathrm{aq} \text {, init }}=\left[\mathrm{H}^{+}\right]_{\mathrm{aq}}+$ $[\mathrm{HA}]_{\mathrm{aq}}$, and $\left[\mathrm{Cl}^{-}\right]_{\mathrm{aq}, \text { init }}=\left[\mathrm{Cl}^{-}\right]_{\mathrm{aq}}$. Also due to the identity of the ionic liquid $\left(\left[\mathrm{A}^{-}\right]_{\mathrm{aq}, \mathrm{IL}}\right)$ and lithium salt $\left(\left[\mathrm{Tf}_{2} \mathrm{~N}^{-}\right]_{\mathrm{aq}, \mathrm{Li}}\left[\mathrm{Tf}_{2} \mathrm{~N}\right]\right)$ anions, the total equilibrium aqueous concentration of organic anions was measured, where $\left[\mathrm{Tf}_{2} \mathrm{~N}^{-}\right]_{\mathrm{aq}}$, total $=\left[\mathrm{Tf}_{2} \mathrm{~N}^{-}\right]_{\mathrm{aq}, \mathrm{Li}}\left[\mathrm{Tf}_{2} \mathrm{~N}\right]$ $+\left[\mathrm{A}^{-}\right]_{\mathrm{aq}, \mathrm{IL}}$.

Therefore, subtraction of eq 20 from eq 19 leads to

$$
[\mathrm{HA}]_{\mathrm{aq}}-\left[\mathrm{C}^{+}\right]_{\mathrm{aq}}=\Delta\left[\mathrm{Tf}_{2} \mathrm{~N}^{-}\right]_{\mathrm{aq}}+z \Delta\left[\mathrm{S}^{z-}\right]_{\mathrm{aq}}
$$

where $\Delta\left[\mathrm{Tf}_{2} \mathrm{~N}^{-}\right]_{\mathrm{aq}}=\left[\mathrm{Tf}_{2} \mathrm{~N}^{-}\right]_{\mathrm{aq} \text {, init }}-\left[\mathrm{Tf}_{2} \mathrm{~N}^{-}\right]_{\mathrm{aq} \text {, total }}$.

Thus, a combination of eqs 18 and 21 results in a quadratic equation:

$$
\begin{aligned}
& K_{s p}^{\prime}=\left(\left[\mathrm{H}^{+}\right]_{a q}\left[\mathrm{~A}^{-}\right]_{a q} K_{a}^{-1}-\Delta\left[\mathrm{Tf}_{2} N^{-}\right]_{a q}-z \Delta\left[\mathrm{S}^{z-}\right]_{a q}\right) \\
& {\left[\mathrm{A}^{-}\right]_{a q}\left(1+\left[\mathrm{H}^{+}\right]_{a q} K_{a}^{-1}\right)}
\end{aligned}
$$

Let $\left[\mathrm{T}^{-}\right]_{\mathrm{aq}}=\Delta\left[\mathrm{Tf}_{2} \mathrm{~N}^{-}\right]_{\mathrm{aq}}+z \Delta\left[\mathrm{S}^{z-}\right]_{\mathrm{aq}}$. The solution to this equation is therefore

$$
\left[\mathrm{A}^{-}\right]_{a q}=\frac{\left[\mathrm{T}^{-}\right]_{a q}+\left(\left[\mathrm{T}^{-}\right]_{a q}{ }^{2}+4\left(K_{a}+\left[\mathrm{H}^{+}\right]_{a q}\right)^{-1}\left[\mathrm{H}^{+}\right]_{a q} K_{s p}^{\prime}\right)^{0.5}}{2\left[\mathrm{H}^{+}\right]_{a q} K_{a}^{-1}}
$$

Effect of $\mathrm{Li}\left[\mathrm{Tf}_{2} \mathrm{~N}\right]$ on $\mathrm{Tl}(\mathrm{III})$ Extraction. In order to confirm the extraction mechanism and determine the charge of the extracted ions, an experiment devoted to introducing $\mathrm{Li}\left[\mathrm{Tf}_{2} \mathrm{~N}\right]$ into the aqueous phase has been performed. In our experiment, the initial aqueous concentration of stable $\mathrm{Tl}$ (III) was constant $\left(\sim 10^{-4} \mathrm{M}\right)$ and the only variable is the concentration of $\mathrm{Li}\left[\mathrm{Tf}_{2} \mathrm{~N}\right]$ in the aqueous phase. In the case of $\mathrm{Tl}(\mathrm{III})$ extraction, strictly speaking $\left[\mathrm{T}^{-}\right]_{\mathrm{aq}}=\Delta\left[\mathrm{Tf}_{2} \mathrm{~N}^{-}\right]_{\mathrm{aq}}+$ $z \Delta\left[\mathrm{TlCl}_{3+z}{ }^{z-}\right]_{\mathrm{aq}}$, although $\Delta\left[\mathrm{TlCl}_{3+z}{ }^{z-}\right]_{\mathrm{aq}}$ is negligible and can be eliminated.

Figure 10 shows the $\mathrm{Tl}(\mathrm{III})$ extraction behavior without an oxidizing agent as a function of the concentration difference

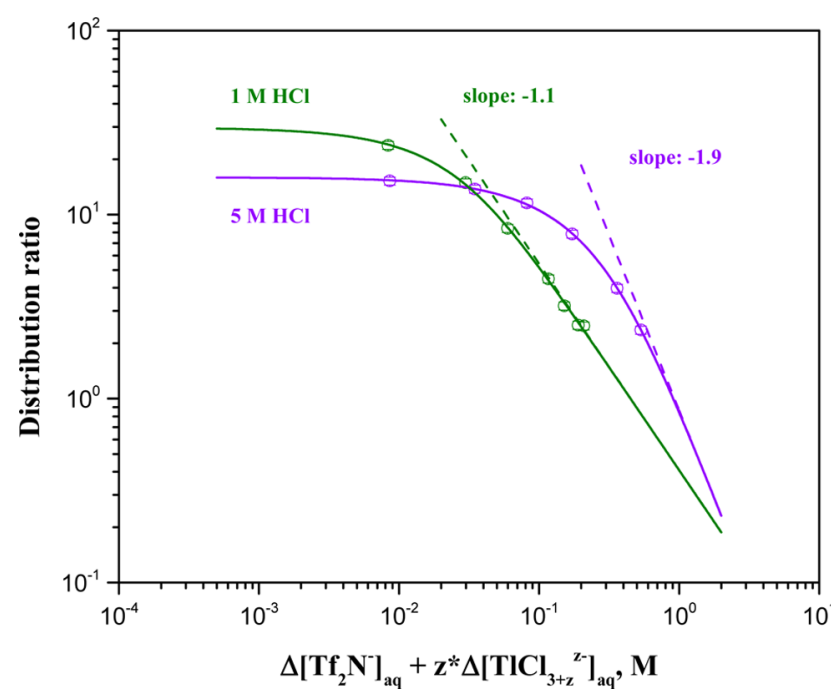

Figure 10. Extraction of stable $\mathrm{Tl}(\mathrm{III})$ without an oxidizing agent from 1 and $5 \mathrm{M} \mathrm{HCl}$ into $\left[\mathrm{C}_{4} \mathrm{mim}\right]\left[\mathrm{Tf}_{2} \mathrm{~N}\right]$ as a function of added $\mathrm{Li}\left[\mathrm{Tf}_{2} \mathrm{~N}\right]$ (solid lines). The tangents (dashed lines) are discussed in the main text.

between initially added $\mathrm{Li}\left[\mathrm{Tf}_{2} \mathrm{~N}\right]$ and stable $\mathrm{Tl}(\mathrm{III})$ and the equilibrium concentration of $\left[\mathrm{Tf}_{2} \mathrm{~N}^{-}\right]$and $\mathrm{Tl}(\mathrm{III})$, namely $\Delta\left[\mathrm{Tf}_{2} \mathrm{~N}^{-}\right]_{\mathrm{aq}}+\mathrm{z} \Delta\left[\mathrm{TlCl}_{3+z} z-\right]_{\mathrm{aq}}$ (these parameters were directly measured by NMR and ICP-MS), in the aqueous phase for both 1 and $5 \mathrm{M} \mathrm{HCl}$. It can be seen that distribution ratio values of $\mathrm{Tl}(\mathrm{III})$ in the $\left[\mathrm{C}_{4} \mathrm{mim}\right]\left[\mathrm{Tf}_{2} \mathrm{~N}\right]$ ionic liquid phase 
decrease with increasing $\Delta\left[\mathrm{Tf}_{2} \mathrm{~N}^{-}\right]_{\mathrm{aq}}$. All of the $D_{\mathrm{Tl}(\mathrm{III})}$ values are below those for the corresponding $\mathrm{Tl}$ extraction into $\left[\mathrm{C}_{4} \mathrm{mim}\right]\left[\mathrm{Tf}_{2} \mathrm{~N}\right]$ in the absence of the lithium salt in the aqueous phase (see Figure 7). It should be noted that there is clear evidence of the influence of $\mathrm{HCl}$ concentration on $\mathrm{Tl}$ (III) extraction, which might be explained in terms of different speciation of the extracted metal.

In order to fit the experimental data in Figure 10, a combined equation based on eqs 17 and 23 has been used. The equilibrium concentration of protons was determined as $\left[\mathrm{H}^{+}\right]_{a q}$ $=\left[\mathrm{H}^{+}\right]_{a q, \text { init }}\left(1+\left[\mathrm{A}^{-}\right]_{a q} K_{a}^{-1}\right)^{-1}$, where $\left[\mathrm{A}^{-}\right]_{a q}$ was found to be independent of acid concentration and equal to $20 \mathrm{mM}$ in up to $5 \mathrm{M} \mathrm{HCl}$ solution. Also, the lower limit of the modified solubility product, $K_{\text {sp }}^{\prime}$, was set to $2.7 \times 10^{-4}$, because this is the solubility product of the $\left[\mathrm{C}_{4} \mathrm{mim}\right]\left[\mathrm{Tf}_{2} \mathrm{~N}\right]$ ionic liquid in water. $^{70}$ The nonlinear fitting process was performed in Origin 8.5 software. The best fit provides parameters that minimize deviations of the theoretical curve from the experimental points, according to the so-called Pearson's chi-squared test. An iterative strategy to estimate the parameter values leads to the reduced chi-square, which is the mean deviation for all data points. Table 2 gives the results of fitting the data in Figure 10.

Table 2. Fitted Parameters for the $\mathrm{Tl}(\mathrm{III}) / \mathrm{HCl} / \mathrm{Li}\left[\mathrm{Tf}_{2} \mathrm{~N}\right] / /$ $\left[\mathrm{C}_{4} \mathrm{mim}\right]\left[\mathrm{Tf}_{2} \mathbf{N}\right]$ System $^{a}$

\begin{tabular}{lll} 
parameter & \multicolumn{1}{c}{$1 \mathrm{M} \mathrm{HCl}$} & \multicolumn{1}{c}{$5 \mathrm{M} \mathrm{HCl}$} \\
reduced $\chi^{2}$ & 0.703 & 0.069 \\
$z$ & $1.12 \pm 0.06$ & $1.97 \pm 0.16$ \\
$K_{s p}^{\prime}$ & $(8.3 \pm 2.5) \times 10^{-4}$ & $0.064 \pm 0.013$ \\
$K_{I E}^{\prime}$ & $0.75 \pm 0.06$ & $1.22 \pm 0.02$ \\
$K_{I P}$ & $2160 \pm 250$ & $273 \pm 10$
\end{tabular}

$a_{\text {The data are presented in Figure } 10 .}$

We also graphically determined the average charge of the complexes of interest by measuring the tangents to the curves at high $\left[\mathrm{Tf}_{2} \mathrm{~N}^{-}\right]$concentrations in Figure 10 . The corresponding slopes in 1 and $5 \mathrm{M} \mathrm{HCl}$ were -1.1 and -1.9 , respectively. The calculated $z$ values in Table 2 are in agreement with the graphically found ones and are likely more accurate and clearly indicate on the average charge of extracted thallium complexes: in $1 \mathrm{M} \mathrm{HCl}$, we mostly extracted $\mathrm{TlCl}_{4}{ }^{-}$, and in $5 \mathrm{M} \mathrm{HCl}$, we extracted either $\mathrm{TlCl}_{5}{ }^{2-}$ or a mixture of $\mathrm{TlCl}_{4}{ }^{-}$and $\mathrm{TlCl}_{6}{ }^{3-}$ with an almost $1: 1$ ratio. $\left(\mathrm{Br}^{-}\right.$was not present in these experiments). The $K_{s p}^{\prime}$ values show that the modified solubility product increased as expected with increasing $\mathrm{HCl}$ concentration, and both values are greater than $K_{\text {sp }}^{\prime}$ calculated for the same ionic liquid in contact with $0.1 \mathrm{M} \mathrm{HCl}$, which is equal to $3.5 \times 10^{-4}$. $^{73}$ The ion pair formation equilibrium constant $K_{I P}$ has been found to be at least 2 orders of magnitude greater than the ion exchange equilibrium constant $K_{I E}^{\prime}$ in both cases. This indicates that the ion pair formation process is predominant in the $\mathrm{Tl}$ (III) extraction process into pure ILs. In other words, the formation of the $\left[\mathrm{C}_{4} \mathrm{mim}^{+}\right]\left[\mathrm{TlCl}_{4}{ }^{-}\right]$ion pair in $1 \mathrm{M} \mathrm{HCl}$ and the $\left[\mathrm{C}_{4} \mathrm{mim}^{+}\right]_{2}\left[\mathrm{TlCl}_{5}{ }^{2-}\right]$ ion pair or a mixture of $\left[\mathrm{C}_{4} \mathrm{mim}^{+}\right]\left[\mathrm{TlCl}_{4}{ }^{-}\right]$and $\left[\mathrm{C}_{4} \mathrm{mim}^{+}\right]_{3}\left[\mathrm{TlCl}_{6}{ }^{3-}\right]$ in $5 \mathrm{M} \mathrm{HCl}$ is much more favorable than $\left[\mathrm{Tf}_{2} \mathrm{~N}^{-}\right]$exchange with $\mathrm{Tl}(\mathrm{III})$ anionic complexes. The formation of these complexes is not surprising because compounds of similar structure are known and well characterized, for example $\left[\mathrm{C}_{2} \mathrm{mim}\right]\left[\mathrm{AlCl}_{4}\right]{ }^{76}$ $\left[\mathrm{C}_{n} \mathrm{mim}\right]_{2}\left[\mathrm{NiCl}_{4}\right](n=4-8),{ }^{77}$ and $\left[\mathrm{C}_{8} \mathrm{mim}\right]_{2}\left[\mathrm{Ce}\left(\mathrm{NO}_{3}\right)_{6}\right]^{53}$ We have also observed similar ion pair products in an ancillary experiment when the $\left[\mathrm{C}_{10} \mathrm{mim}\right] \mathrm{Cl}$ ionic liquid was added to a
$5.4 \mathrm{mM} \mathrm{Tl}(\mathrm{III})$ solution in $1 \mathrm{M} \mathrm{HCl}$. It was found that a new phase (insoluble in the aqueous solution) was formed, which was easily dissolved upon the addition of the $\left[\mathrm{C}_{10} \mathrm{mim}\right]\left[\mathrm{Tf}_{2} \mathrm{~N}\right]$ ionic liquid. The content of this new phase was likely $\left[\mathrm{C}_{10} \mathrm{mim}\right]\left[\mathrm{TlCl}_{4}\right]$.

TI(III) Loading. The loading of stable thallium should be considered in order to determine the range of metal concentration in the organic phase after extraction, to avoid the possibility of third phase formation. It was found that the extracted complex is soluble in the ionic liquid phase without any sign of third phase formation. Figure 11 shows measured

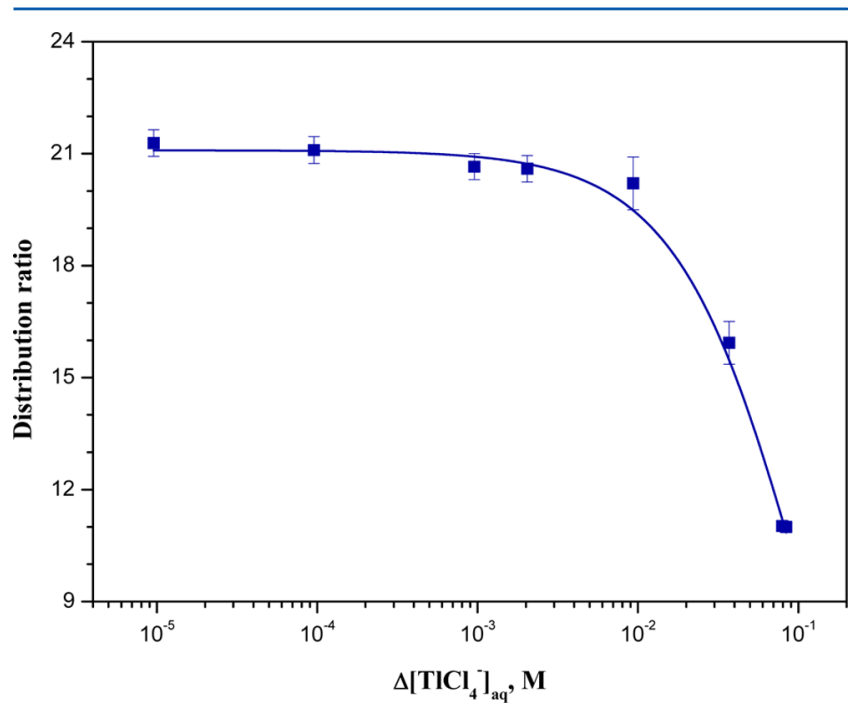

Figure 11. Distribution ratio of $\mathrm{Tl}(\mathrm{III})$ between $\left[\mathrm{C}_{2} \mathrm{mim}\right]\left[\mathrm{Tf}_{2} \mathrm{~N}\right]$ ionic liquid and $0.5 \mathrm{M} \mathrm{HCl}$ as a function of differences between initial and equilibrium concentrations of stable $\mathrm{Tl}(\mathrm{III})$ in the aqueous phase.

$D_{\mathrm{Tl}(\mathrm{III})}$ values and it can be seen that the $\mathrm{Tl}$ (III) extraction does not depend on metal concentration in the aqueous phase in the range of up to $1 \times 10^{-3} \mathrm{M}$. Thus, this value determines the capacity of the organic phase.

In order to fit these experimental data, eq 23 has been slightly modified with respect to absence of $\mathrm{Li}\left[\mathrm{Tf}_{2} \mathrm{~N}\right]$ and presence of stable $\mathrm{Tl}(\mathrm{III})$ in $0.5 \mathrm{M} \mathrm{HCl}$ in the only form of $\mathrm{TlCl}_{4}^{-}(z=1)$ :

$$
\left[\mathrm{A}^{-}\right]_{a q}=\frac{\Delta\left[\mathrm{TlCl}_{4}{ }^{-}\right]_{a q}+\left(\Delta\left[\mathrm{TlCl}_{4}{ }^{-}\right]_{a q}{ }^{2}+4 K_{s p}^{\prime}\right)^{0.5}}{2\left(1+\left[\mathrm{H}^{+}\right]_{a q} K_{a}^{-1}\right)}
$$

Thus, parameters for $\left[\mathrm{C}_{2} \mathrm{mim}\right]\left[\mathrm{Tf}_{2} \mathrm{~N}\right]$ ionic liquid in $0.5 \mathrm{M}$ $\mathrm{HCl}$ have been measured: $K_{\text {sp }}^{\prime}=(3.45 \pm 0.14) \times 10^{-3}, K_{\mathrm{IE}}^{\prime}=$ $1.24 \pm 0.02$, and $K_{\mathrm{IP}}=359 \pm 10$. The solubility product value is consistent with the higher solubility of $\left[\mathrm{C}_{2} \mathrm{mim}\right]\left[\mathrm{Tf}_{2} \mathrm{~N}\right]$ compared to $\left[\mathrm{C}_{4} \mathrm{mim}\right]\left[\mathrm{Tf}_{2} \mathrm{~N}\right]$. Also, the results confirm that ion pair formation is predominant in this system as well.

$\mathrm{TI}(\mathrm{III})$ Back-Extraction. It can be seen from Figure 9 that $\mathrm{Tl}(\mathrm{III})$ can be easily back-extracted by increasing the $\mathrm{HCl}$ concentration. Back-extraction of $\mathrm{Tl}(\mathrm{III})$ with $10.2 \mathrm{M} \mathrm{HCl}$ was tested for the $\left[\mathrm{C}_{4} \mathrm{mim}\right]\left[\mathrm{Tf}_{2} \mathrm{~N}\right]$ ionic liquid after extraction of the metal from a $1 \mathrm{M} \mathrm{HCl}$ solution. Distribution ratio values of $\mathrm{Tl}$ (III) were successfully decreased by a single back-extraction from 100 (bromine water used as thallium oxidizer in forward extraction) and 60 (chlorine water used as thallium oxidizer) to 10 and 9, respectively, and these results are in good agreement with the data shown in Figure 7. The data indicate that in terms of extraction chromatography, if ionic liquids were attached to 
an inert support and packed into a column, efficient elution of thallium from the column can be expected.

In order to back-extract $\mathrm{Tl}$ in the case of very high $D_{\mathrm{Tl}(\mathrm{III})}$ values (i.e., from $\left[\mathrm{C}_{8} \mathrm{mim}\right]\left[\mathrm{Tf}_{2} \mathrm{~N}\right]$ ionic liquid phases after extraction), its reduction to the +1 oxidation state can be an alternative technique, because stripping with even highly concentrated aqueous $\mathrm{HCl}$ solutions will not allow one to reach distribution ratio values below 10. For example, a previous publication $^{78}$ successfully applied hydrazine to reduce the thallium oxidation state.

\section{CONCLUSIONS}

Extraction of both $\mathrm{Tl}(\mathrm{I})$ and $\mathrm{Tl}(\mathrm{III})$ from $\mathrm{HCl}$ media into a series of pure hydrophobic ionic liquids has been investigated. It has been shown that distribution ratios attributed to $\mathrm{Tl}(\mathrm{I})$ are below 1 and the structure of ionic liquid noticeably affects the extraction efficiency. It has been observed that the longer alkyl chains of imidazolium-based ILs correspond to lower extractions of cationic $\mathrm{Tl}^{+}$species at low acidities, while at high $\mathrm{HCl}$ concentrations, the extraction is insensitive to the alkyl chain length of $\left[\mathrm{C}_{n} \mathrm{mim}\right]\left[\mathrm{Tf}_{2} \mathrm{~N}\right](n=2,4$, and 8$)$. In the case of $\mathrm{Tl}(\mathrm{III})$, surprisingly high extraction efficiencies and fast kinetics have been observed, and equilibrium has been reached in seconds. The influence of ionic liquid structure on the extraction of $\mathrm{TlX}_{3+z} z^{-}$complexes (where $\mathrm{X}=\mathrm{Cl}^{-}$and/or $\mathrm{Br}^{-}$) is the opposite of $\mathrm{Tl}^{+}$. It has been found that the $\mathrm{Tl}$ (III) extraction ability of ionic liquids in this work increases in the order $\left[\mathrm{C}_{2} \mathrm{mim}\right]\left[\mathrm{Tf}_{2} \mathrm{~N}\right]<\left[\mathrm{C}_{3} \mathrm{C}_{1}\right.$ pyrr $]\left[\mathrm{Tf}_{2} \mathrm{~N}\right]<\left[\mathrm{C}_{4} \mathrm{mim}\right]\left[\mathrm{Tf}_{2} \mathrm{~N}\right]$ $<\left[\mathrm{C}_{2} \mathrm{mim}\right][\mathrm{FSI}]<\left[\mathrm{C}_{3} \mathrm{C}_{1} \mathrm{mim}\right]\left[\mathrm{Tf}_{2} \mathrm{~N}\right]<\left[\mathrm{C}_{8} \mathrm{mim}\right]\left[\mathrm{Tf}_{2} \mathrm{~N}\right]$. The solubilities of the $\left[\mathrm{Tf}_{2} \mathrm{~N}^{-}\right]$-based ionic liquids in water decrease in the same order. The charge of the $\mathrm{Tl}(\mathrm{III})$ complexes has been determined by introduction of $\mathrm{Li}\left[\mathrm{Tf}_{2} \mathrm{~N}\right]$ into the aqueous phase for experiments with $\left[\mathrm{Tf}_{2} \mathrm{~N}^{-}\right]$-based ionic liquids. The measured data indicated that the extraction of $\mathrm{Tl}(\mathrm{III})$ proceeds mainly via ion pair complex formation with IL cations, and that the extracted metallic species are $\mathrm{TlCl}_{4}{ }^{-}$in low acid concentrations and either $\mathrm{TlCl}_{5}{ }^{2-}$ or a mixture of $\mathrm{TlCl}_{4}{ }^{-}$and $\mathrm{TlCl}_{6}^{3-}$ in high acid concentrations. It has been noted that $\mathrm{Tl}(\mathrm{III})$ extraction is quantitative for initial metal concentrations up to $1 \times 10^{-3} \mathrm{M}$. Back-extraction of $\mathrm{Tl}$ (III) has been checked based on the influence of $\mathrm{HCl}$ concentration, and a successful decrease in distribution ratio values has been observed. In total, these results indicate that the use of pure ionic liquids for extraction of $\mathrm{Tl}$ from aqueous $\mathrm{HCl}$ solutions is feasible.

\section{ASSOCIATED CONTENT}

\section{S Supporting Information}

The Supporting Information is available free of charge on the ACS Publications website at DOI: 10.1021/acs.jpcb.5b08924.

Figure comparing distribution ratios using ionic liquids with two and four carbon substituents to the imidazolium ring while $\mathrm{Tl}$ was oxidized by either bromine or chlorine water (PDF)

\section{AUTHOR INFORMATION}

\section{Corresponding Author}

*(C.M.F.) Telephone: (979) 845-1411. Fax: (979) 845-1899

E-mail: Folden@comp.tamu.edu.

\section{Notes}

The authors declare no competing financial interest.

\section{ACKNOWLEDGMENTS}

The authors thank Sylvia Georg (IPHC, Strasbourg) for performing the ICP-MS measurements. This work was supported by the Centre National de la Recherche Scientifique of France (CNRS) and the University of Strasbourg. This material is based upon work supported by the U.S. Department of Energy, Office of Science, Office of Nuclear Physics under Award Number DE-FG02-12ER41869/DE-SC0008126. Additionally, this work was supported by the Robert A. Welch Foundation under Award Number A-1710. Finally, we acknowledge funding provided by Lawrence Livermore $\mathrm{Na}$ tional Laboratory to support collaborative research at Texas A\&M University.

\section{REFERENCES}

(1) Thallium: 2015 World Market Review and Forecast; http:// mcgroup.co.uk/researches/thallium-market, 2015; p 45.

(2) Mortada, W. I.; Kenawy, I. M.; Hassanien, M. M. A Cloud Point Extraction Procedure for Gallium, Indium and Thallium Determination in Liquid Crystal Display and Sediment Samples. Anal. Methods 2015, 7, 2114-2120.

(3) Shcherbakov, A. S.; Maximov, J.; Bliznetsov, A. M.; Perez, K. J. S. Potentials of Acousto-Optical Spectrum Analysis on a Basis of a Novel Algorithm of the Collinear Wave Heterodyning in a Large-Aperture KRS-5 Crystalline Cell. Opt. Eng. 2011, 50, 034002.

(4) Agrawal, B. K.; Singh, V.; Srivastava, R.; Agrawal, S. Structural, Electronic and Optical Properties of Ultrathin Thallium Nanowires an Ab Initio Study. Philos. Mag. 2007, 87, 2335-2353.

(5) Kinsey, V. E.; McLean, I. W.; Parker, J. Studies on the Crystalline Lens. 18. Kinetics of Thallium $\left(\mathrm{Tl}^{+}\right)$Transport in Relation to That of the Alkali Metal Cations. Invest. Ophthalmol. 1971, 10, 932-942.

(6) Barone-Rochette, G.; Leclere, M.; Calizzano, A.; Vautrin, E.; Celine, G. C.; Broisat, A.; Ghezzi, C.; Baguet, J. P.; Machecourt, J.; Vanzetto, G.; et al. Stress Thallium-201/Rest Technetium-99m Sequential Dual-Isotope High-Speed Myocardial Perfusion Imaging Validation Versus Invasive Coronary Angiography. J. Nucl. Cardiol. 2015, 22, 513-522.

(7) Drozdovitch, V.; Brill, A. B.; Callahan, R. J.; Clanton, J. A.; DePietro, A.; Goldsmith, S. J.; Greenspan, B. S.; Gross, M. D.; Hays, M. T.; Moore, S. C.; et al. Use of Radiopharmaceuticals in Diagnostic Nuclear Medicine in the United States: 1960-2010. Health Phys. 2015, 108, 520-537.

(8) Krasikova, R. N.; Kodina, G. E. Radionuclides and Radiopharmaceuticals for Single-Photon Emission Tomography, Positron Emission Tomography and Radiotherapy in Russia. Eur. J. Nucl. Med. Mol. Imaging 1999, 26, 774-788.

(9) Rickwood, C. J.; King, M.; Huntsman-Mapila, P. Assessing the Fate and Toxicity of Thallium I and Thallium III to Three Aquatic Organisms. Ecotoxicol. Environ. Saf. 2015, 115, 300-308.

(10) Rodriguez-Mercado, J. J.; Altamirano-Lozano, M. A. Genetic Toxicology of Thallium: A Review. Drug Chem. Toxicol. 2013, 36, 369-383.

(11) Zitko, V. Toxicity and Pollution Potential of Thallium. Sci. Total Environ. 1975, 4, 185-192.

(12) Augustynowicz, J.; Tokarz, K.; Baran, A.; Plachno, B. J. Phytoremediation of Water Polluted by Thallium, Cadmium, Zinc, and Lead with the Use of Macrophyte Callitriche Cophocarpa. Arch. Environ. Contam. Toxicol. 2014, 66, 572-581.

(13) Xiao, T.; Yang, F.; Li, S.; Zheng, B.; Ning, Z. Thallium Pollution in China: A Geo-Environmental Perspective. Sci. Total Environ. 2012, 421-422, 51-58.

(14) Grahn, E.; Karlsson, S.; Karlsson, U.; Duker, A. Historical Pollution of Seldom Monitored Trace Elements in Sweden - Part B: Sediment Analysis of Silver, Antimony, Thallium and Indium. J. Environ. Monit. 2006, 8, 732-744.

(15) Huang, C.; Zhang, X.; Li, G.; Jiang, Y.; Wang, Q.; Tian, R. A Case of Severe Thallium Poisoning Successfully Treated with 
Hemoperfusion and Continuous Veno-Venous Hemofiltration. Hum. Exp. Toxicol. 2014, 33, 554-558.

(16) Li, J. M.; Wang, W.; Lei, S.; Zhao, L. L.; Zhou, D.; Xiong, H. Misdiagnosis and Long-Term Outcome of 13 Patients with Acute Thallium Poisoning in China. Clin. Toxicol. 2014, 52, 181-186.

(17) Moore, D.; House, I.; Dixon, A.; Williams, G.; Volans, G.; Henry, J.; Hughes, R.; Cochrane, G.; Atkinson, P.; Milburn, H. Thallium Poisoning. BMJ 1993, 306, 1527-1529.

(18) Lee, J. H.; Kim, D. J.; Ahn, B. K. Distributions and Concentrations of Thallium in Korean Soils Determined by Single and Sequential Extraction Procedures. Bull. Environ. Contam. Toxicol. 2015, 94, 756-763.

(19) Turner, A.; Turner, D.; Braungardt, C. Biomonitoring of Thallium Availability in Two Estuaries of Southwest England. Mar. Pollut. Bull. 2013, 69, 172-177.

(20) Miyazaki, A.; Kimura, A.; Tao, H. Distribution of Indium, Thallium and Bismuth in the Environmental Water of Japan. Bull. Environ. Contam. Toxicol. 2012, 89, 1211-1215.

(21) Queirolo, F.; Stegen, S.; Contreras-Ortega, C.; Ostapczuk, P.; Queirolo, A.; Paredes, B. Thallium Levels and Bioaccumulation in Environmental Samples of Northern Chile. J. Chil. Chem. Soc. 2009, 54, 464-469.

(22) Tao, Z.; Gameiro, A.; Grewer, C. Thallium Ions Can Replace Both Sodium and Potassium Ions in the Glutamate Transporter Excitatory Amino Acid Carrier. Biochemistry 2008, 47, 12923-12930.

(23) Hassler, C. S.; Chafin, R. D.; Klinger, M. B.; Twiss, M. R. Application of the Biotic Ligand Model to Explain Potassium Interaction with Thallium Uptake and Toxicity to Plankton. Environ. Toxicol. Chem. 2007, 26, 1139-1145.

(24) Lan, C. H.; Lin, T. S. Acute Toxicity of Trivalent Thallium Compounds to Daphnia Magna. Ecotoxicol. Environ. Saf. 2005, 61, 432-435.

(25) Ralph, L.; Twiss, M. R. Comparative Toxicity of Thallium(I), Thallium(III), and Cadmium(II) to the Unicellular Alga Isolated from Lake Erie. Bull. Environ. Contam. Toxicol. 2002, 68, 0261-0268.

(26) Pandey, G. P.; Singh, A. K.; Prasad, S.; Deshmukh, L.; Asthana, A. Development of Surfactant Assisted Kinetic Method for Trace Determination of Thallium in Environmental Samples. Microchem. J. 2015, 118, 150-157.

(27) Agnihotri, N. K.; Singh, V. K.; Ratnani, S.; Shukla, S. K.; Parashar, G. K. A Method for Nonextractive Simultaneous Determination of Thallium (III) and Gallium (III) in Environmental and Standard Samples with 2-(5-Bromo-2-Pyridylazo)-5-Diethylaminophenol in Cationic Micellar Medium. Anal. Lett. 2004, 37, 25152529.

(28) Altundag, H.; Dundar, M. S. Determination of Thallium after Preconcentration on Amberlite IR-120 by ICP-MS. Fresenius Environ. Bull. 2009, 18, 98-101.

(29) Hassanien, M. M.; Kenawy, I. M.; El-Menshawy, A. M.; ElAsmy, A. A. Separation and Preconcentration of Gallium(III), Indium(III), and Thallium(III) Using New Hydrazone-Modified Resin. Anal. Sci. 2007, 23, 1403-1408.

(30) Fazelirad, H.; Taher, M. A. Ligandless, Ion Pair-Based and Ultrasound Assisted Emulsification Solidified Floating Organic Drop Microextraction for Simultaneous Preconcentration of Ultra-Trace Amounts of Gold and Thallium and Determination by GFAAS. Talanta 2013, 103, 375-383.

(31) Chamsaz, M.; Arbab-Zavar, M. H.; Darroudi, A.; Salehi, T. Preconcentration of Thallium (I) by Single Drop Microextraction with Electrothermal Atomic Absorption Spectroscopy Detection Using Dicyclohexano-18-Crown-6 as Extractant System. J. Hazard. Mater. 2009, 167, 597-601.

(32) Stojanovic, A.; Keppler, B. K. Ionic Liquids as Extracting Agents for Heavy Metals. Sep. Sci. Technol. 2012, 47, 189-203.

(33) Sun, X. Q.; Luo, H. M.; Dai, S. Ionic Liquids-Based Extraction: A Promising Strategy for the Advanced Nuclear Fuel Cycle. Chem. Rev. 2012, 112, 2100-2128.
(34) Ho, T. D.; Zhang, C.; Hantao, L. W.; Anderson, J. L. Ionic Liquids in Analytical Chemistry: Fundamentals, Advances, and Perspectives. Anal. Chem. 2014, 86, 262-285.

(35) Handy, S. T. Applications of Ionic Liquids in Science and Technology; InTech: Rijeka, Croatia, 2011; p 516.

(36) Papaiconomou, N.; Lee, J.-M.; Salminen, J.; von Stosch, M.; Prausnitz, J. M. Selective Extraction of Copper, Mercury, Silver, and Palladium Ions from Water Using Hydrophobic Ils. Ind. Eng. Chem. Res. 2008, 47, 5080-5086.

(37) Popa, A.; Ciopec, M.; Negrea, A.; Lupa, L.; Negrea, P.; Davidescu, C. M.; Ilia, G.; Duteanu, N. Use of StyreneDivinylbenzene Grafted with Aminoethylaminomethyl Groups and Various Ionic Liquids in the Removal Process of Thallium and Strontium. Pure Appl. Chem. 2014, 86, 1741-1753.

(38) Nadiki, H. H.; Taher, M. A.; Ashkenani, H. Ionic Liquid Ultrasound Assisted Dispersive Liquid-Liquid/Micro-Volume Back Extraction Procedure for Preconcentration and Determination of Ultra Trace Amounts of Thallium in Water and Biological Samples. Int. J. Environ. Anal. Chem. 2013, 93, 623-636.

(39) Anthemidis, A. N.; Ioannou, K. I. Sequential Injection Ionic Liquid Dispersive Liquid-Liquid Microextraction for Thallium Preconcentration and Determination with Flame Atomic Absorption Spectrometry. Anal. Bioanal. Chem. 2012, 404, 685-691.

(40) Escudero, L. B.; Wuilloud, R. G.; Olsina, R. A. Sensitive Determination of Thallium Species in Drinking and Natural Water by Ionic Liquid-Assisted Ion-Pairing Liquid-Liquid Microextraction and Inductively Coupled Plasma Mass Spectrometry. J. Hazard. Mater. 2013, 244-245, 380-386.

(41) Escudero, L. B.; Berton, P.; Martinis, E. M.; Olsina, R. A.; Wuilloud, R. G. Dispersive Liquid-Liquid Microextraction and Preconcentration of Thallium Species in Water Samples by Two Ionic Liquids Applied as Ion-Pairing Reagent and Extractant Phase. Talanta 2012, 88, 277-283.

(42) Tereshatov, E. E.; Boltoeva, M. Yu.; Folden, C. M., III Resin Ion Exchange and Liquid-Liquid Extraction of Indium and Thallium from Chloride Media. Solvent Extr. Ion Exch. 2015, 33, 607-624.

(43) de los Rios, A. P.; Hernandez-Fernandez, F. J.; Alguacil, F. J.; Lozano, L. J.; Ginesta, A.; Garcia-Diaz, I.; Sanchez-Segado, S.; Lopez, F. A.; Godinez, C. On the Use of Imidazolium and Ammonium-Based Ionic Liquids as Green Solvents for the Selective Recovery of $\mathrm{Zn}$ (II), $\mathrm{Cd}(\mathrm{II}), \mathrm{Cu}(\mathrm{II})$ and $\mathrm{Fe}(\mathrm{III})$ from Hydrochloride Aqueous Solutions. Sep. Purif. Technol. 2012, 97, 150-157.

(44) Papaiconomou, N.; Billard, I.; Chainet, E. Extraction of Iridium(IV) from Aqueous Solutions Using Hydrophilic/Hydrophobic Ionic Liquids. RSC Adv. 2014, 4, 48260-48266.

(45) Génand-Pinaz, S.; Papaiconomou, N.; Leveque, J.-M. Removal of Platinum from Water by Precipitation or Liquid-Liquid Extraction and Separation from Gold Using Ionic Liquids. Green Chem. 2013, 15, 2493-2501.

(46) Zhang, C.; Huang, K.; Yu, P.; Liu, H. Ionic Liquid Based ThreeLiquid-Phase Partitioning and One-Step Separation of Pt (IV), Pd (II) and Rh (III). Sep. Purif. Technol. 2013, 108, 166-173.

(47) Papaiconomou, N.; Genand-Pinaz, S.; Leveque, J. M.; Guittonneau, S. Selective Extraction of Gold and Platinum in Water Using Ionic Liquids. A Simple Two-Step Extraction Process. Dalton Trans. 2013, 42, 1979-1982.

(48) Papaiconomou, N.; Vite, G.; Goujon, N.; Lévêque, J.-M.; Billard, I. Efficient Removal of Gold Complexes from Water by Precipitation or Liquid-Liquid Extraction Using Ionic Liquids. Green Chem. 2012, 14, 2050-2056.

(49) Papaiconomou, N.; Glandut, N.; Billard, I.; Chainet, E. Unusual Electrochemical Behaviour of $\mathrm{AuBr}_{4}{ }^{-}$in Ionic Liquids. Towards a Simple Recovery of Gold(III) after Extraction into an Ionic Liquid. RSC Adv. 2014, 4, 58910-58915.

(50) Germani, R.; Mancini, M. V.; Savelli, G.; Spreti, N. Mercury Extraction by Ionic Liquids: Temperature and Alkyl Chain Length Effect. Tetrahedron Lett. 2007, 48, 1767-1769. 
(51) Mancini, M. V.; Spreti, N.; Di Profio, P.; Germani, R. Understanding Mercury Extraction Mechanism in Ionic Liquids. Sep. Purif. Technol. 2013, 116, 294-299.

(52) Mohammadi, S. Z.; Afzali, D.; Fallahi, Z. Ionic Liquid-Based Dispersive Liquid-Liquid Microextraction for the Separation and Preconcentration of Lead in Water Samples Prior to FAAS Determination without Chelating Agent. Int. J. Environ. Anal. Chem. 2014, 94, 765-773.

(53) Zuo, Y.; Liu, Y.; Chen, J.; Li, D. Q. The Separation of Cerium(IV) from Nitric Acid Solutions Containing Thorium(IV) and Lanthanides(III) Using Pure $\left[\mathrm{C}_{8} \mathrm{mim}\right]\left[\mathrm{PF}_{6}\right]$ as Extracting Phase. Ind. Eng. Chem. Res. 2008, 47, 2349-2355.

(54) Jensen, M. P.; Neuefeind, J.; Beitz, J. V.; Skanthakumar, S.; Soderholm, L. Mechanisms of Metal Ion Transfer into RoomTemperature Ionic Liquids: The Role of Anion Exchange. J. Am. Chem. Soc. 2003, 125, 15466-15473.

(55) Rout, A.; Venkatesan, K. A.; Srinivasan, T. G.; Vasudeva Rao, P. R. Unusual Extraction of Plutonium(IV) from Uranium(VI) and Americium(III) Using Phosphonate Based Task Specific Ionic Liquid. Radiochim. Acta 2010, 98, 459-466.

(56) Ansari, S. A.; Mohapatra, P. K.; Mazan, V.; Billard, I. Extraction of Actinides by Tertiary Amines in Room Temperature Ionic Liquids: Evidence for Anion Exchange as a Major Process at High Acidity and Impact of Acid Nature. RSC Adv. 2015, 5, 35821-35829.

(57) Mazan, V.; Billard, I.; Papaiconomou, N. Experimental Connections between Aqueous-Aqueous and Aqueous-Ionic Liquid Biphasic Systems. RSC Adv. 2014, 4, 13371-13384.

(58) Ranke, J.; Othman, A.; Fan, P.; Muller, A. Explaining Ionic Liquid Water Solubility in Terms of Cation and Anion Hydrophobicity. Int. J. Mol. Sci. 2009, 10, 1271-1289.

(59) Strelow, F. W. E.; Victor, A. H.; van Zyl, C. R.; Eloff, C. Distribution Coefficients and Cation Exchange Behavior of Elements in Hydrochloric Acid-Acetone. Anal. Chem. 1971, 43, 870-876.

(60) 2480 Wizard Automatic Gamma Counter, Perkin Elmer; http:// www.perkinelmer.com/catalog/product/id/2480-0010.

(61) Tereshatov, E. E.; Folden, C. M., III A Labview Solution for Coupling an Automated Gamma-Ray Counter and Software for Spectra Analysis; Texas A\&M University, Cyclotron Institute: Progress in Research Report; 2015, Section IV, pp IV66-IV74: http://cyclotron. $\mathrm{t}$ a m u.e d u / $2015 \% 20 \mathrm{Prog}$ re s s $\% 20 \mathrm{Report} /$ $4 \% 20$ Superconducting $\% 20$ Cyclotron\%20and\%20Instrumentation/IV_ 66-74 a\%20labview\%20solution.pdf.

(62) Read, A. J.; Aldridge, L. P. Thallous Chloride Complexes in 0 to 6 Molal Sodium Chloride at $25{ }^{\circ}$ C. J. Solution Chem. 1992, 21, 12311239

(63) Dietz, M. L.; Stepinski, D. C. Anion Concentration-Dependent Partitioning Mechanism in the Extraction of Uranium into RoomTemperature Ionic Liquids. Talanta 2008, 75, 598-603.

(64) Gaillard, C.; Boltoeva, M.; Billard, I.; Georg, S.; Mazan, V.; Ouadi, A.; Ternova, D.; Hennig, C. Insights into the Mechanism of Extraction of Uranium (VI) from Nitric Acid Solution into an Ionic Liquid by Using Tri-N-Butyl Phosphate. ChemPhysChem 2015, 16, $2653-2662$.

(65) Stability Constants of Metal-Ion Complexes; Special Publication No. 17; The Chemical Society: London, 1964; p 754.

(66) Glaser, J. On the Structures of the Thallium(III) Chloride Complexes in Solution. I. Evidence for Tetrahedral $\mathrm{TlCl}_{4}{ }^{-}$and Octahedral $\mathrm{TlCl}_{6}^{3-}$ Species in Aqueous Solution. Acta Chem. Scand. 1982, A36, 451-458.

(67) Glaser, J.; Johansson, G. On the Structures of the Hydrated Thallium(III) Ion and Its Bromide Complexes in Aqueous Solution. Acta Chem. Scand. 1982, A36, 125-135.

(68) Dupont, D.; Depuydt, D.; Binnemans, K. Overview of the Effect of Salts on Biphasic Ionic Liquid/Water Solvent Extraction Systems: Anion Exchange, Mutual Solubility, and Thermomorphic Properties. J. Phys. Chem. B 2015, 119, 6747-6757.

(69) Janssen, C. H. C.; Sanchez, A.; Witkamp, G. J.; Kobrak, M. N. A

Novel Mechanism for the Extraction of Metals from Water to Ionic Liquids. ChemPhysChem 2013, 14, 3806-3813.
(70) Katsuta, S.; Nakamura, K.; Kudo, Y.; Takeda, Y. Mechanisms and Rules of Anion Partition into Ionic Liquids: Phenolate Ions in Ionic Liquid/Water Biphasic Systems. J. Phys. Chem. B 2012, 116, 852-859.

(71) Watanabe, Y.; Katsuta, S. Distribution of a Monovalent Anion in Various Ionic Liquid/Water Biphasic Systems: Relationship of the Distribution Ratio of Picrate Ions with the Aqueous Solubility of Ionic Liquids. J. Chem. Eng. Data 2014, 59, 696-701.

(72) Hamamoto, T.; Okai, M.; Katsuta, S. The Laws Governing Ionic Liquid Extraction of Cations: Partition of 1-Ethylpyridinium Monocation and Paraquat Dication in Ionic Liquid/Water Biphasic Systems. J. Phys. Chem. B 2015, 119, 6317-6325.

(73) Katsuta, S.; Watanabe, Y.; Araki, Y.; Kudo, Y. Extraction of Gold(III) from Hydrochloric Acid into Various Ionic Liquids: Relationship between Extraction Efficiency and Aqueous Solubility of Ionic Liquids. ACS Sustainable Chem. Eng. 2016, 4, 564-571.

(74) Sun, T.; Shen, X.; Chen, Q. A Further Understanding of the Cation Exchange Mechanism for the Extraction of $\mathrm{Sr}^{2+}$ and $\mathrm{Cs}^{+}$by Ionic Liquid. Sci. China: Chem. 2013, 56, 782-788.

(75) Gaillard, C.; Mazan, V.; Georg, S.; Klimchuk, O.; Sypula, M.; Billard, I.; Schurhammer, R.; Wipff, G. Acid Extraction to a Hydrophobic Ionic Liquid: The Role of Added Tributylphosphate Investigated by Experiments and Simulations. Phys. Chem. Chem. Phys. 2012, 14, 5187-5199.

(76) Binnemans, K. Lanthanides and Actinides in Ionic Liquids. Chem. Rev. 2007, 107, 2592-2614.

(77) Meredith, M. B.; McMillen, C. H.; Goodman, J. T.; Hanusa, T. P. Ambient Temperature Imidazolium-Based Ionic Liquids with Tetrachloronickelate(II) Anions. Polyhedron 2009, 28, 2355-2358.

(78) van der Walt, T. N.; Naidoo, C. Recovery of ${ }^{201} \mathrm{Tl}$ by Ion Exchange Chromatography from Proton Bombarded Thallium Cyclotron Targets. Radiochim. Acta 2000, 88, 185-187. 